This manuscript is a preprint that has been peer-reviewed and accepted for publication in APPLIED OCEAN RESEARCH. Once published, the final version of this manuscript will be available via the 'Peer-reviewed Publication DOI' link on the right-hand side of this webpage. Please feel free to contact any of the authors; we welcome feedback. 


\title{
Modelling an energetic tidal strait: investigating implications of common numerical configuration choices
}

\author{
Lucas Mackie $^{\mathrm{a}, *}$, Paul S. Evans ${ }^{\mathrm{b}}$, Magnus J. Harrold ${ }^{\mathrm{c}}$, Tim O’Doherty ${ }^{\mathrm{d}}$, Matthew D. Piggott ${ }^{\mathrm{a}}$, Athanasios \\ Angeloudis ${ }^{\mathrm{e}}$ \\ ${ }^{a}$ Department of Earth Science $\&$ Engineering, Imperial College London, London, UK \\ ${ }^{b}$ Intertek Energy 85 Water, The Maltings, Cardiff, CF24 5EA, UK \\ ${ }^{c}$ Offshore Renewable Energy Catapult, Pembroke Dock, UK \\ ${ }^{d}$ School of Engineering, Cardiff University, The Parade, Cardiff CF24 3AA, UK \\ ${ }^{e}$ School of Engineering, Institute for Infrastructure 85 the Environment, The University of Edinburgh, Edinburgh, UK
}

\begin{abstract}
Representation of the marine environment is key for reliable coastal hydrodynamic models. This study investigates the implications of common depth-averaged model configuration choices in sufficiently characterising seabed geometry and roughness. In particular, applications requiring a high level of accuracy and/or exhibiting complex flow conditions may call for greater detail in marine environment representation than typically adopted in coastal models. Ramsey Sound, a macrotidal strait in Pembrokeshire, Wales, UK is considered as a case study. The site contains various steeply inclined bathymetric features, including a submerged pinnacle named Horse Rock and a rocky reef called "The Bitches". The available energy in Ramsey Sound's tidal currents has attracted attention from tidal energy developers. There is interest in accurately modelling the energetic hydrodynamics surrounding its pronounced bathymetry. The coastal flow solver Thetis is applied to simulate the flow conditions in Ramsey Sound. It is shown that notable prominent bathymetric features in the strait influence localised and, most importantly, regional hydrodynamic characteristics. "The Bitches" consistently accelerate flow in the strait while Horse Rock induces a notable wake structure and flow reversals. The model is calibrated against bed- and vessel-mounted Acoustic Doppler Current Profiler (ADCP) observations, by altering seabed roughness parameterisations. A spatially variable and locally scaled Manning coefficient based on diverse seabed classification observations is found to improve model performance in comparison to uniformly applied constants, the latter a more common approach. The local impact of altering the Manning coefficient configuration is found to be greatest during spring flood periods of high velocity currents. Meanwhile, the effect of coarsening the computational mesh around bathymetric features towards values more typically applied in coastal models is investigated. Results indicate severe misrepresentation of seabed geometry and subsequent wake hydrodynamics unless refined to a mesh element size that adequately represents Horse Rock and "The Bitches".
\end{abstract}

Keywords: Coastal hydrodynamics, model calibration, Manning coefficient, unstructured mesh, field measurements, wake modelling, marine energy.

\section{Introduction}

Depth-averaged modelling is widely used in analysing coastal hydrodynamics. The computational efficiency and accuracy afforded by two-dimensional numerical models [1] renders them suitable for a variety

\footnotetext{
${ }^{*}$ Corresponding author

Email addresses: 1.mackie18@imperial.ac.uk (Lucas Mackie), a.angeloudis@ed.ac.uk (Athanasios Angeloudis)
} 
of industry and research applications, including marine engineering [2, 3], morphological [4] and ecological

5 5. 5 studies. Characterisation of the marine environment is a key component of depth-averaged models. This methodical study questions model configuration choices regarding seabed depth (bathymetry) and roughness. Simplifications in their representation may inhibit the ability to sufficiently calibrate against field measurements in certain sites. This is particularly relevant where complex flow conditions exist and/or a high degree of accuracy is required.

The case study of Ramsey Sound, a tidal strait on the Welsh coastline, is considered. Ramsey Sound has been identified by the UK government as a prime candidate site for the deployment of tidal stream turbines 6]. Tidal Energy Ltd previously explored the viability of the strait in terms of its energy output by testing a single 400kW DeltaStream device [7]. The highly dynamic flow characteristics posed challenges to the timing of maintenance activities and disrupted operation, thus hindering commercial progress. As a result, further 15 insight into these flow conditions merits research to inform future commercial activities in highly energetic and challenging sites that are focal for the development of the marine energy industry.

Ramsey Sound contains a number of pronounced bathymetric features. Evans et al. [8] discusses how one of these features, a submerged natural pinnacle called Horse Rock, generates a wake exhibiting substantial velocity deficits. Tidal stream devices located in wake regions could experience operational performance 9 , in addition to highly dynamic local flow structures [10, could potentially contribute to turbine failure [11. Accurately characterising field-based wakes is a demanding task. Irregular bathymetry and asymmetrical coastlines disturb wake structure such that quantification of the free-stream velocity downstream of the structure becomes challenging. Flow in the wake of idealised submerged obstacles has been studied experi25 mentally [12, and by numerical modelling [13]. These studies highlight the complexity of unsteady flow and its sensitivity to a series of site-specific parameters. Field characteristics of these flows are poorly understood as relatively few field-based modelling studies of the wake characteristics of submerged natural obstacles have been undertaken 8$]$.

Overall, the strait presents a non-trivial case for exploring the validity of common configuration choices in depth-averaged models. Regional scale coastal ocean domains typically exhibit well-mixed conditions, allowing a depth-averaged representation of the water column. However, two previous case studies of Ramsey Sound recommend 3D modelling to characterise local hydrodynamics [7, 8]. Haverson et al. 7] studied morphological impacts of turbine arrays, while Evans et al. 8] analysed a comprehensive Acoustic Doppler Current Profiler (ADCP) survey to investigate turbine considerations regarding flow conditions around Horse

35 Rock. Yet the favourable efficiency of depth-averaging offers numerous additional modelling possibilities, such as advanced tidal turbine array optimisation [14, 15, 16. The challenging conditions in this site therefore provide an opportunity to explore the limitations of depth-averaged coastal ocean models applying detailed representation of the marine environment.

The first common depth-averaged modelling configuration choice investigated in this paper considers the numerical representation of seabed roughness. Thiébot et al. 4] and Guillou and Chapalain [17] both acknowledge the heterogeneous nature of bottom sediments in hydrodynamic modelling of sediment transport in the English Channel. However, it is more common for depth-averaged modelling studies to spatially apply seabed roughness coefficient as a uniform constant [18, 19. In addition, tidal stream turbine models typically consider friction coefficient variation solely through additional momentum sinks as parameterisations for 45 turbines [7, 20, 3, 21. Yet significant seabed sediment type variability exists in the Irish Sea [22, 23]. The effectiveness and/or limitations of calibrating a depth-averaged model against field measurements, through applying Manning coefficient variability, warrants analysis.

The second model configuration refinement investigated herein concerns spatial discretisation. Depth- 
averaged modelling studies often discretise the domain horizontally by an unstructured mesh to represent the ${ }_{50}$ irregular shape of the coastline. These multi-scale numerical models typically refine the mesh to a greater extent in areas of interest, balancing computational cost and/or simplicity with field measurement configuration precision. Given the short distance over which Horse Rock protrudes horizontally (50 m diameter at half height), the minimum mesh element length $\wedge h(\mathrm{~m})$ applied in similar regional, coastal or ocean models would severely misrepresent its shape (e.g., $\wedge h=50 \mathrm{~m} \mathrm{[24],} \wedge h=125 \mathrm{~m}$ [18], $\wedge h=300 \mathrm{~m}[20$ ], $\wedge h=250 \mathrm{~m}$ [25], $\wedge h=200 \mathrm{~m}$ [19]). The application of a similar mesh structure in Ramsey Sound could therefore easily under- and/or over-appreciate Horse Rock's localised and regional hydrodynamic impact. In tidal resource assessment studies, the finest part of the mesh is often reserved for turbine deployment zones, as opposed to areas containing prominent bathymetric features $(\wedge h=18 \mathrm{~m}$ [21]). This increases the likelihood that an obstruction with similar geometry to Horse Rock would remain under-resolved.

${ }_{60}$ This study investigates model configuration in the context of Thetis (http://thetisproject.org/), a 2-D/3-D model for simulating coastal and estuarine flows. Thetis is implemented using the Firedrake finite element Partial Differential Equation (PDE) solver framework [1, 26, 27]. Given certain methodological similarities between Thetis and other commonly applied coastal modelling platforms (e.g. MIKE21 [28] and Delft3D [29]), findings herein will be of relevance to other depth-averaged coastal ocean modelling packages. straits containing similar bathymetric features. This work highlights the importance of considering the characterisation of influential and location-specific features; an act that might be hindered by common model simplifications. It is therefore anticipated that the results presented here are transferable to a diverse range of coastal domains. Nevertheless, other potential tidal-energy sites identified in the UK [30], such as the Pentland Firth [20, Rathlin Sound [18] and Kyle Rhea [8], also have physical characteristics similar to those of Ramsey Sound.

\section{Case study location: Ramsey Sound, Wales, UK}

Ramsey Sound is a tidal strait approximately $3 \mathrm{~km}$ long, ranging in width from $500-1600 \mathrm{~m}$. It is connected to the Irish Sea and separates Ramsey Island from the headland of St. David's, Pembrokeshire, Wales (Fig.

75 11. Key physical characteristics of the tidal strait have previously been noted by Evans et al. 8], and can be observed in Fig. 22. The water depth generally varies between 20-40 m below Lowest Astronomical Tide (LAT) - also commonly referred to as Chart Datum (CD) - but reaches a maximum depth of $66 \mathrm{~m}$ LAT within a north-south trending trench. A roughly conical submerged pinnacle called Horse Rock dominates the northern portion of the strait. It rises $23 \mathrm{~m}$ above the surrounding seabed and has diameters of $\sim 100$ $\mathrm{m}$ at base and $\sim 50 \mathrm{~m}$ at half height. According to Admiralty Charts, it pierces the water at $+0.9 \mathrm{~m}$ LAT [31]. Finally, a shallow rocky reef named "The Bitches" contributes to the narrowing of the straight towards the southern section [8].

Tidal hydrodynamics in the wider Irish sea stem from the superposition of two Kelvin-type waves, resulting in zones of negligible tidal range but strong tidal currents [33. Within Ramsey Sound, tidal elevations are a

${ }_{85}$ result of a progressive tidal wave regime, with peak velocities occurring at high and low tide [34. The $M_{2}$ tidal constituent is dominant, with a period of approximately $12.42 \mathrm{~h}$ [35]. The strong semi-diurnal tide drives a tidal range of approximately 1.6-5 m from mean neap to mean spring, current speeds exceeding $3 \mathrm{~ms}^{-1}$ and zones of high turbulence [36. Regional flood tide (northwards) velocities are higher than equivalent stages in the spring-neap cycle on the ebb tide. This asymmetry is dictated by the phase relationship between the $M_{2}$ and $M_{4}$ tidal constituents [35, 37. The local influence of $M_{4}$ is highlighted by its contribution of \pm 0.14 $\mathrm{ms}^{-1}$ to tidal currents at one survey location in Ramsey Sound, where $M_{2}$ exhibits $\pm 2.00 \mathrm{~ms}^{-1}[38$. 



Figure 1: Domain and computational mesh for Ramsey Sound and surrounding seas. Mesh element size ranges between a maximum of $8 \mathrm{~km}$ in the open ocean, $1 \mathrm{~km} / 300 \mathrm{~m}$ at coastlines outside/inside of Pembrokeshire, $50 \mathrm{~m}$ around small islands and $25 \mathrm{~m}$ around Ramsey Sound. A minimum mesh element size $\wedge h$ is applied in areas exhibiting high bathymetry gradients in and around Ramsey Sound. In frames a), c) and d), $\wedge h=8 \mathrm{~m}, \mathrm{e}) \wedge h=16 \mathrm{~m}, \mathrm{f}) \wedge h=32 \mathrm{~m}$ and $\mathrm{g}) \wedge h=64 \mathrm{~m}$. Also indicated are tide gauge locations 32 used for tide constituent validation in the model.

\section{Methodology}

\subsection{D hydrodynamic modelling}

Thetis is configured to solve the non-conservative form of the nonlinear shallow water equations:

$$
\begin{gathered}
\frac{\partial \eta}{\partial t}+\nabla \cdot\left(H_{d} \tilde{\mathbf{u}}\right)=0 \\
\frac{\partial \tilde{\mathbf{u}}}{\partial t}+\tilde{\mathbf{u}} \cdot \nabla \tilde{\mathbf{u}}-\nu \nabla^{2} \tilde{\mathbf{u}}+f \tilde{\mathbf{u}}^{\perp}+g \nabla \eta=-\frac{\tau_{b}}{\rho H_{d}},
\end{gathered}
$$



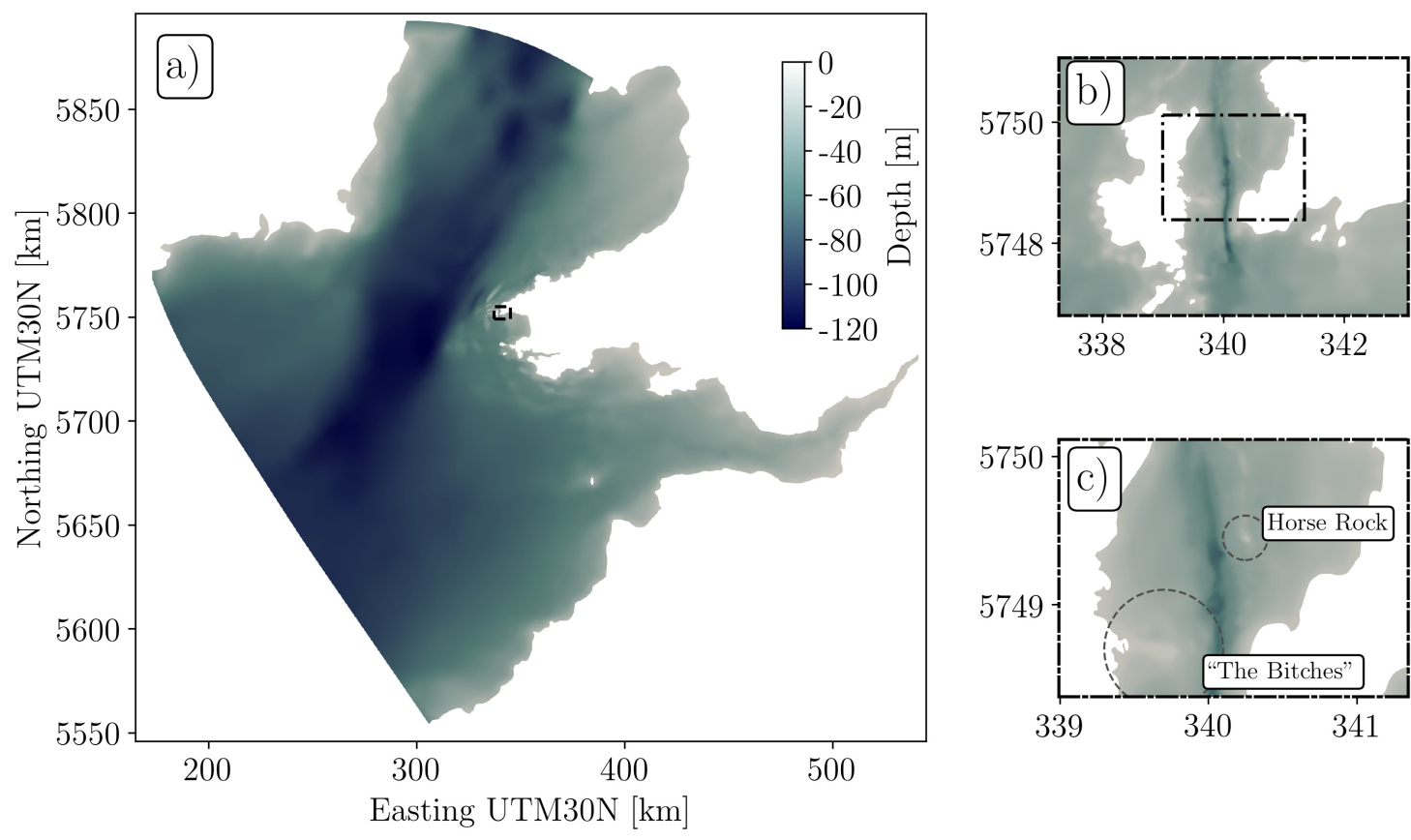

Figure 2: Bathymetry field measurements interpolated onto the computational mesh, corrected to Mean Sea Level (MSL) (m). Frames b) and c) indicate Ramsey Sound with Horse Rock and "The Bitches" labelled. The north-south trench can also be observed down the centre-line of the strait.

$$
\frac{\tau_{b}}{\rho}=g n^{2} \frac{|\tilde{\mathbf{u}}| \tilde{\mathbf{u}}}{H_{d}^{\frac{1}{3}}},
$$

95 where $\eta(\mathrm{m})$ is the water elevation, $H_{d}(\mathrm{~m})$ is the total water depth, $\nu\left(\mathrm{m}^{2} \mathrm{~s}^{-1}\right)$ is the kinematic viscosity of the fluid and $\tilde{\mathbf{u}}\left(\mathrm{ms}^{-1}\right)$ the depth-averaged velocity vector with horizontal components $\tilde{u}$ and $\tilde{v}$ depicting easterly and northerly flow, respectively. The term $f \tilde{\mathbf{u}}^{\perp}$ represents the Coriolis "force", where $\tilde{\mathbf{u}}^{\perp}$ is the velocity vector rotated counter-clockwise over $90^{\circ}$ and $f=2 \Omega \sin (\zeta)$, in which $\Omega$ is the angular frequency of the Earth's rotation and $\zeta$ is latitude. Seabed roughness effects are represented via Manning's formulation (3) for bed shear stress $\tau_{b}\left(\mathrm{kgm}^{-1} \mathrm{~s}^{-2}\right)$, using the Manning coefficient $n\left(\mathrm{sm}^{-1 / 3}\right)$. Intertidal processes are treated using the wetting and drying formulation detailed in Kärnä et al. 39]. Wind or wave effects are not included in the model in this work.

The model solver is configured similarly to other tidal resource characterisation studies which apply Thetis 2, 5, 40, 41]. A discontinuous Galerkin finite element spatial discretisation (DG-FEM) is utilised through the choice of a $P_{1 D G}-P_{1 D G}$ velocity-pressure finite element pair. A semi-implicit Crank-Nicolson timestepping approach is applied. The nonlinear discretised shallow water equations are iteratively solved with Newton's algorithm using the PETSc library [42.

\subsubsection{Computational domain}

The mesh generation framework qmesh (https://www.qmesh.org/, 43]), which applies the meshing tool Gmsh [4], is employed to produce unstructured meshes to represent the domain. This domain spans a large section of the Irish Sea, encompassing parts of the Celtic Sea and Northern Channel, as indicated in Fig. 17. A finer resolution is applied along the coastlines to capture intertidal processes [39]. The mesh is further refined around bathymetric features in Ramsey Sound which are of interest (Fig. 1d). Here, a minimum 
mesh element size of $\wedge h=8 \mathrm{~m}$ is applied, an appropriate size locally as indicated by Haverson et al. [7], who implemented $\wedge h=10 \mathrm{~m}$ in these areas.

Bathymetry field measurements from multiple sources inform the hydrodynamic model (Fig. 2). Measurements for the majority of the domain are obtained from the Edina Digimap Service 45. A resolution of $1 / 3600^{\circ}$ (ranging from $18 \mathrm{~m}$ to $20 \mathrm{~m}$ in the model domain) is applied where possible and $1 / 600^{\circ}$ (111 $\mathrm{m}$ to $119 \mathrm{~m}$ ) otherwise. An $11 \times 12 \mathrm{~km}$ rectangle around Ramsey Sound is covered by a $2 \mathrm{~m}$ resolution bathymetry survey from the UK Hydrographic Office (UKHO) 46. All bathymetry is configured to the UTM zone 30N projection. Converting LAT (Lowest Astronomical Tide) to MSL in the z-direction made use of tide constituent observations $\left(Q_{1}, O_{1}, P_{1}, K_{1}, N_{2}, M_{2}, S_{2}, K_{2}\right)$ from TPXO [47]. An overview of the bathymetry field applied in the model is given on Fig. 2. In addition, the TPXO framework is used to force the model at the ocean boundaries using the same tidal constituents 47. Tidal forcing is the primary model component which aligns the model to a specific moment in time. While the effects of the $M_{4}$ tidal constituent are noticable in Ramsey Sound itself [35, it is primarily a shallow water harmonic [48] and therefore negligable at the ocean boundaries.

Particular attention is paid to the characterisation of Horse Rock. Notable discrepancies occur between representation of this feature in the $2 \mathrm{~m}$ resolution UKHO survey and other accounts [49]. The UKHO observations indicate that Horse Rock does not pierce the water surface, with the tip reaching -1.21 m LAT. Admiralty Charts indicate a depth of $+0.9 \mathrm{~m}$ LAT [31, suggesting drying at spring tide lows also observed in video footage of the area [49]. As the bathymetry survey from the UKHO was conducted on a vessel, it is likely that capturing the tip of Horse Rock would not have been possible. The tip of Horse Rock is therefore raised to $+0.9 \mathrm{~m}$ LAT by incorporating an artificial conical feature on the top.
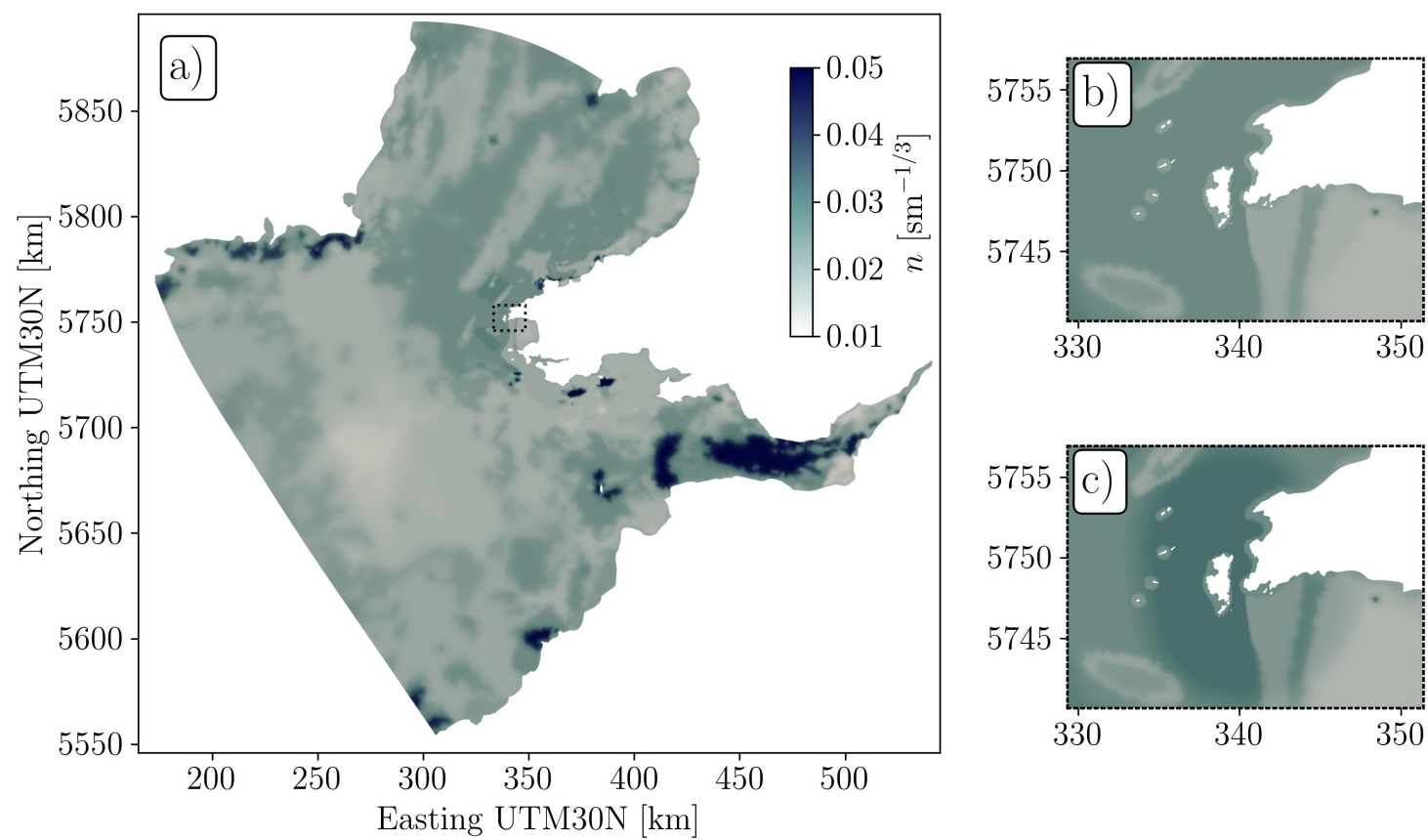

Figure 3: Manning $n$ coefficient calculated using observations from the British Geological Survey interpolated as a variable field denoted by $N$ onto computational mesh domain. c) indicates variable scaling field $N^{*}$, with Manning coefficient amplified locally to Ramsey Sound within $10 \mathrm{~km}$ radius of Horse Rock, converging towards $N$ over a further $2 \mathrm{~km}$. 


\subsubsection{Calibrating the representation of bed shear stress}

Bed classification observations are sourced from the British Geological Survey (BGS) to inform grain size $d_{50}(\mathrm{~mm})$ [50] across the domain. Coastal areas where observations are unavailable are estimated to have a grain size $d_{50}=6 \mathrm{~mm}$, equivalent to "small gravel". In determining a relationship between bed classification and Manning coefficient $n\left(\mathrm{sm}^{-1 / 3}\right)$ (Table 1 ), the Nikuradse parameter for sand grain roughness is calculated through $k_{s}=2.5 d_{50}$. Roughness length $z_{0}(\mathrm{~m})$ (the height above the seabed where fluid velocity is zero) is subsequently determined determined with $z_{0}=\frac{k_{s}}{30}$, followed by Manning coefficient with $n=0.04 \sqrt[6]{k_{s}}[51$. Fig. $3 \mathrm{a}-\mathrm{b}$ shows the spatial application of the variable Manning coefficient field, denoted as $N$. Scaling of $N$ is used as a tuning parameter in the calibration process, as either a constant scaling applied throughout the domain (e.g. $1.25 \mathrm{~N}$ ), or as a scale factor applied locally in the area of interest (e.g. $1.25 \mathrm{~N}^{*}$ in Fig. 3).

Table 1: British Geological Survey bed classification and associated grain size $d_{50}(\mathrm{~mm})$ observations subsequently applied in calculating roughness length $z_{0}(\mathrm{~mm})$ and Manning coefficient $n\left(\mathrm{sm}^{-1 / 3}\right)$.

\begin{tabular}{l|c|c|c}
\hline \hline Bed classification & $d_{50}(\mathrm{~mm})$ & $z_{0}(\mathrm{~mm})$ & $n\left(\mathrm{sm}^{-1 / 3}\right)$ \\
\hline Bedrock & $768 \geq d_{50}>2048$ & $64.00 \geq z_{0}>170.7$ & $0.045 \geq n>0.053$ \\
Boulder & $256 \geq d_{50}>768$ & $21.33 \geq z_{0}>64.00$ & $0.037 \geq n>0.045$ \\
Cobble & $64 \geq d_{50}>256$ & $5.333 \geq z_{0}>21.33$ & $0.029 \geq n>0.037$ \\
Very coarse gravel & $32 \geq d_{50}>64$ & $2.667 \geq z_{0}>5.333$ & $0.026 \geq n>0.029$ \\
Coarse gravel & $16 \geq d_{50}>32$ & $1.333 \geq z_{0}>2.667$ & $0.023 \geq n>0.026$ \\
Medium gravel & $8 \geq d_{50}>16$ & $0.667 \geq z_{0}>1.333$ & $0.021 \geq n>0.023$ \\
Fine gravel & $4 \geq d_{50}>8$ & $0.333 \geq z_{0}>0.667$ & $0.019 \geq n>0.021$ \\
Very coarse sand & $2 \geq d_{50}>4$ & $0.167 \geq z_{0}>0.333$ & $0.017 \geq n>0.019$ \\
Coarse sand & $1 \geq d_{50}>2$ & $0.083 \geq z_{0}>0.167$ & $0.015 \geq n>0.017$ \\
Medium sand & $0.5 \geq d_{50}>1$ & $0.042 \geq z_{0}>0.083$ & $0.013 \geq n>0.015$ \\
Fine sand & $0.25 \geq d_{50}>0.5$ & $0.021 \geq z_{0}>0.042$ & $0.012 \geq n>0.013$ \\
Very fine sand & $0.125 \geq d_{50}>0.25$ & $0.010 \geq z_{0}>0.021$ & $0.010 \geq n>0.012$ \\
Silt, clay, mud & $0.0625 \geq d_{50}>0.125$ & $0.005 \geq z_{0}>0.010$ & $0.009 \geq n>0.010$ \\
\hline \hline
\end{tabular}

\subsection{Hydrodynamic field observation methods}

Measurements from two acoustic Doppler current profiler (ADCP) surveys [7, 8] support numerical and visual model calibration in this study. Seabed-mounted ADCP velocity measurements were obtained in the north-western portion of Ramsey Sound [52], as indicated in Fig. 4. The instrument sampled at a rate of 1 $\mathrm{Hz}(1 \mathrm{~s})$, recording and averaging at 10 minute intervals (i.e. averaging 600 samples) between 18 February 2009 - 21 March 2009. Meanwhile, vessel-mounted ADCP survey measurements provide a spatially variable representation of tidal conditions in Ramsey Sound. The unit, manufactured by Teledyne RD Instruments and gunwhale-mounted on Cardiff University's research vessel, Guiding Light, was used to conduct surveys across the central portion of Ramsey Sound (Fig. 4). Evans et al. 8] describes the process and challenges encountered when obtaining vessel-mounted ADCP measurements over a set of six transects:

- Transects T1-T3 are surveyed downstream (to the north) of Horse Rock on the flood tide and transects T4-T6 downstream (to the south) of Horse Rock on the ebb tide, indicating northerly and southerly flow, respectively.

- The downstream distance from the idealised transects to Horse Rock varied between $50 \mathrm{~m}$ (T3 and T4), $250 \mathrm{~m}$ (T2 and T5), and $400 \mathrm{~m}$ (T1 and T6).

- The selected days (01 June 2012 for flood tide readings T1-T3 in nine continuous circuits between two slack tides and 02 June 2012 for ebb tide readings T4-T6 in eight continuous circuits between two slack tides) of the survey lie approximately half way between spring and neap tide in the area. 


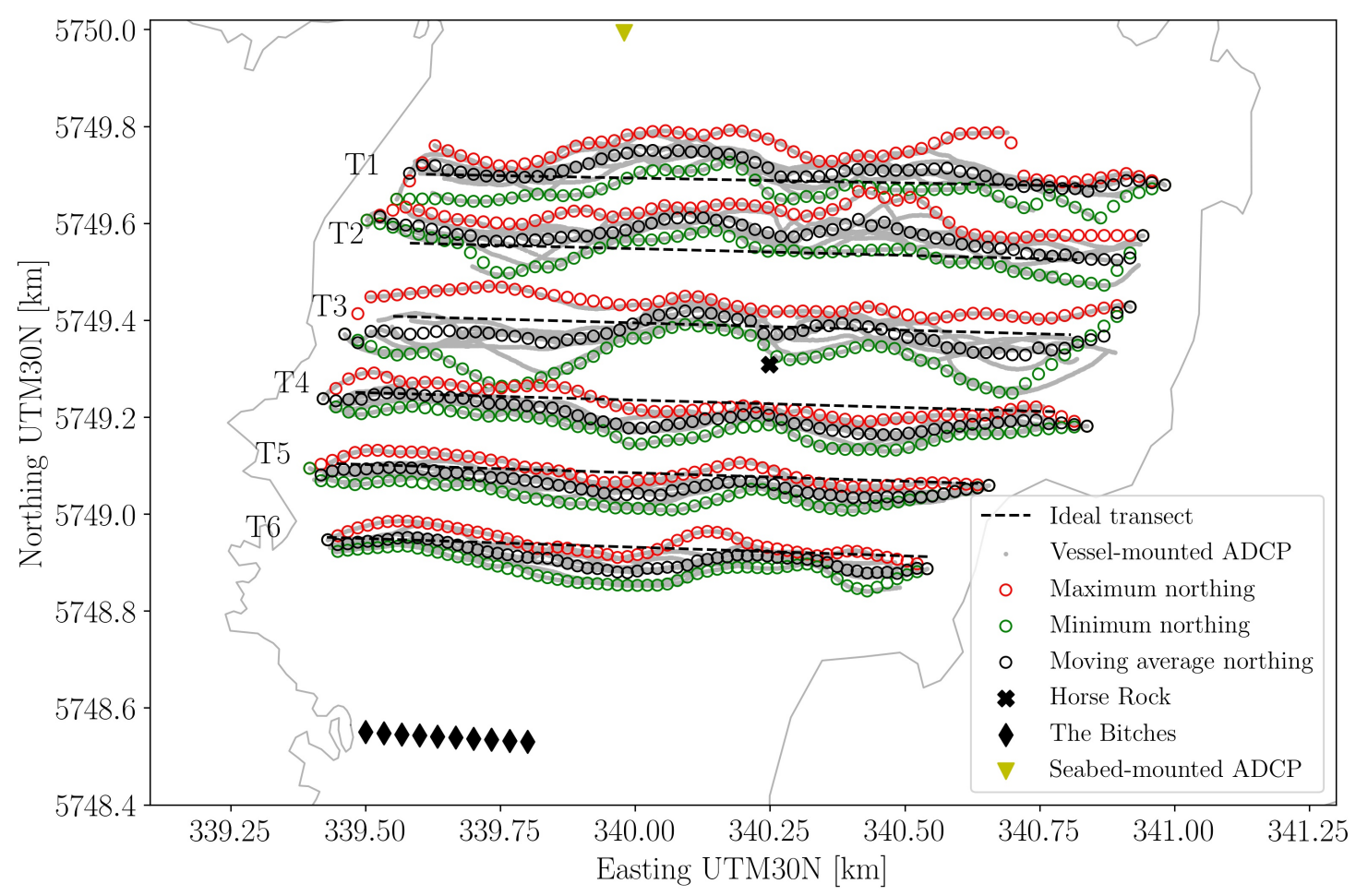

Figure 4: Model sampling locations are established upon navigation of the ADCP vessel. Along each idealised transect, maximum, minimum and average northing values are determined based on evenly spaced easting bins. Easting coordiantes indicate the centre-point of these bins. ADCP measurements at transects T1 to T3 were collected as the tide ebbed, and transects $\mathrm{T} 4$ to $\mathrm{T} 6$ as the tide flooded.

Vessel-mounted ADCP measurements are sub-sampled as the numerical model timestep, $\Delta t$, is much greater than the time difference between ADCP readings. Easterly $u$ and northerly $v$ ADCP velocity measurements are depth-averaged to $\tilde{u}$ and $\tilde{v}$ over the water column and time-averaged to $\tilde{u}_{10}$ and $\tilde{v}_{10}$, the subscript denoting the time-averaging window (s). A $10 \mathrm{~s}$ time-averaging window is deemed appropriate in acknowledging both the spatial and temporal variance of the ADCP measurements. The numerical model is then configured to run for the duration of the vessel-mounted ADCP survey. Noticeable volatility exists in the exact path of each boat circuit along individual transects (Fig. 4), with navigation being complicated by the high current conditions. The average $R^{2}$ correlation coefficient between reading locations on each circuit and the ideal transect is 0.349 . Therefore, to reduce the number of required model monitor points (i.e. virtual gauge/ADCP) locations when calibrating the model against individual ADCP boat circuits, an envelope surrounding the ship-mounted ADCP reading coordinates is generated. Along each transect in a given circuit, all readings are ordered from west to east, with maxima, minima and averages of the boat's northing positions computed within 50 evenly distributed easting bins. In total, this leads to 150 coordinates $(x, y)$ for each transect, combining easting bin mid-points $(x)$ with corresponding maximum, minimum and average northing points $(y)$. The numerical models are set up to extract a time-series of elevation $\eta$ and depth-averaged velocity components $\tilde{u}$ and $\tilde{v}$ for the duration of the simulation at each timestep. ADCP $\tilde{u}_{10}$ and $\tilde{v}_{10}$ are sub-sampled to match the timestepping of the numerical model. Depth-averaged velocity output at the model detector locations positioned closest to the sub-sampled ADCP measurements are then utilised for calibration. 


\section{Results}

In the following section, we explore how model configuration refinements on roughness (Section 3.1.2) and bathymetry representation (Section 3.1.1) affect model outputs. Distinct approaches are adopted in

Table 2: $R^{2}$ correlation coefficient of Thetis model outputs against tide gauge observations, and seabed- and vessel-mounted and ADCP survey measurements. Indicated SI Units don't reflect $R^{2}$ values, as $R^{2}$ is dimensionless.

\begin{tabular}{l|cccccc}
\hline \hline & \multicolumn{5}{|c}{$R^{2}$ correlation coefficient } \\
\hline \hline 1. Tide gauges & $0.02 \mathrm{sm}^{-1 / 3}$ & $0.03 \mathrm{sm}^{-1 / 3}$ & $N$ & $1.25 N$ & $1.5 N$ & $1.25 N^{*}$ \\
\hline$M_{2} \alpha(m)$ & 0.98 & 0.97 & 0.99 & 0.97 & 0.91 & 0.99 \\
$M_{2} \phi\left(^{o}\right)$ & 0.99 & 0.99 & 0.99 & 0.96 & 0.93 & 0.99 \\
$S_{2} \alpha(m)$ & 0.91 & 0.87 & 0.92 & 0.84 & 0.67 & 0.92 \\
$S_{2} \phi\left(^{o}\right)$ & 0.99 & 0.99 & 0.99 & 0.97 & 0.94 & 0.99 \\
\hline \hline 2. Seabed ADCP & $0.02 \mathrm{sm}^{-1 / 3}$ & $0.03 \mathrm{sm}^{-1 / 3}$ & $N$ & $1.25 N$ & $1.5 N$ & $1.25 N^{*}$ \\
\hline$\tilde{u}\left(m s^{-1}\right)$ & 0.08 & 0.09 & 0.09 & 0.14 & 0.16 & 0.11 \\
$\tilde{v}\left(m s^{-1}\right)$ & 0.95 & 0.98 & 0.97 & 0.98 & 0.98 & 0.98 \\
$|\tilde{\mathbf{u}}|\left(m s^{-1}\right)$ & 0.68 & 0.87 & 0.84 & 0.88 & 0.86 & 0.87 \\
$\theta\left({ }^{\circ}\right)$ & 0.94 & 0.95 & 0.95 & 0.95 & 0.95 & 0.96 \\
$\eta(m)$ & 0.99 & 0.99 & 0.99 & 0.99 & 0.99 & 0.99 \\
\hline \hline 3a. Vessel ADCP (Flood) & $0.02 \mathrm{sm}^{-1 / 3}$ & $0.03 \mathrm{sm}^{-1 / 3}$ & $N$ & $1.25 N$ & $1.5 N$ & $1.25 N^{*}$ \\
\hline$\tilde{u}\left(m s^{-1}\right)$ & 0.23 & 0.13 & 0.17 & 0.11 & 0.14 & 0.15 \\
$\tilde{v}\left(m s^{-1}\right)$ & 0.75 & 0.79 & 0.81 & 0.81 & 0.82 & 0.81 \\
$|\tilde{\mathbf{u}}|\left(m s^{-1}\right)$ & 0.71 & 0.74 & 0.77 & 0.76 & 0.79 & 0.77 \\
$\theta\left({ }^{o}\right)$ & 0.83 & 0.90 & 0.88 & 0.91 & 0.91 & 0.91 \\
\hline \hline 3b. Vessel ADCP (Ebb) & $0.02 \mathrm{sm}^{-1 / 3}$ & $0.03 \mathrm{sm}^{-1 / 3}$ & $N$ & $1.25 N$ & $1.5 N$ & $1.25 N^{*}$ \\
\hline$\tilde{u}\left(m s^{-1}\right)$ & 0.21 & 0.53 & 0.43 & 0.56 & 0.51 & 0.51 \\
$\tilde{v}\left(m s^{-1}\right)$ & 0.63 & 0.88 & 0.81 & 0.89 & 0.91 & 0.86 \\
$|\tilde{\mathbf{u}}|\left(m s^{-1}\right)$ & 0.39 & 0.77 & 0.65 & 0.79 & 0.79 & 0.74 \\
$\theta\left(^{o}\right)$ & 0.71 & 0.85 & 0.81 & 0.86 & 0.85 & 0.82 \\
\hline \hline
\end{tabular}

1. Tide gauge observations (BODC): The model simulates 30 days between 27 October 2019 to 26 November 2019, sufficient time to represent a full lunar month and harmonically analyse the free-surface elevation $\eta$. Amplitude $\alpha$ and phase $\phi$ from principal tidal constituents $M_{2}$ and $S_{2}$ are then extracted from the elevation time-series at locationd indicated on Fig. 1. Following timestep sensitivity analyses, 
2. Seabed-mounted ADCP: The seabed-mounted ADCP is situated in the northern section of Ramsey Sound (location Fig. 4). Calibration therefore consists of elevation $\eta$ and depth-averaged velocity (easterly $\tilde{u}$, northerly $\tilde{v}$ and magnitude $|\tilde{\mathbf{u}}|$ ) comparisons at a fixed location. Three days (roughly six tidal cycles) at spring tide are observed, from 00:00 24 February 2009 to 15:20 27 February 2009, with a timestep of $\Delta t=100 \mathrm{~s}$.

3. Vessel-mounted ADCP in a) flood and b) ebb direction: As described in Section 3.2, depthaveraged velocity (easterly $\tilde{u}$, northerly $\tilde{v}$ and magnitude $|\tilde{\mathbf{u}}|$ ) model outputs are compared to depthand time-averaged measurements from the vessel-mounted ADCP survey $\left(\tilde{u}_{10}, \tilde{v}_{10}\right.$ and $\left.\left|\tilde{\mathbf{u}}_{10}\right|\right)$. The entirety of the surveys are considered here, which provide measurements between two slack tides on each of consecutive days. A $\Delta t=50 \mathrm{~s}$ timestep is implemented to provide a higher spatial alignment between field measurements and model outputs. A sensitivity analysis concluded that the difference in output between identical models implementing $\Delta t=50 \mathrm{~s}$ and $\Delta t=100 \mathrm{~s}$ is negligible.

$R^{2}$ correlation coefficient quantifies model effectiveness in capturing measured tidal hydrodynamics. As illustrated in Table 2, high correlation generally exists between modelled and observed free-surface elevation $\eta$, constituent amplitude $\alpha$ and phase $\phi$. Meanwhile, easterly velocity $\tilde{u}$ calibration is quite poor across all models, albeit slightly improved on the ebb tide. The superior correlation observed for $\tilde{v},|\tilde{\mathbf{u}}|$ and $\theta$, indicates the dominance of $\tilde{v}$ in the $|\tilde{\mathbf{u}}|$ vector.
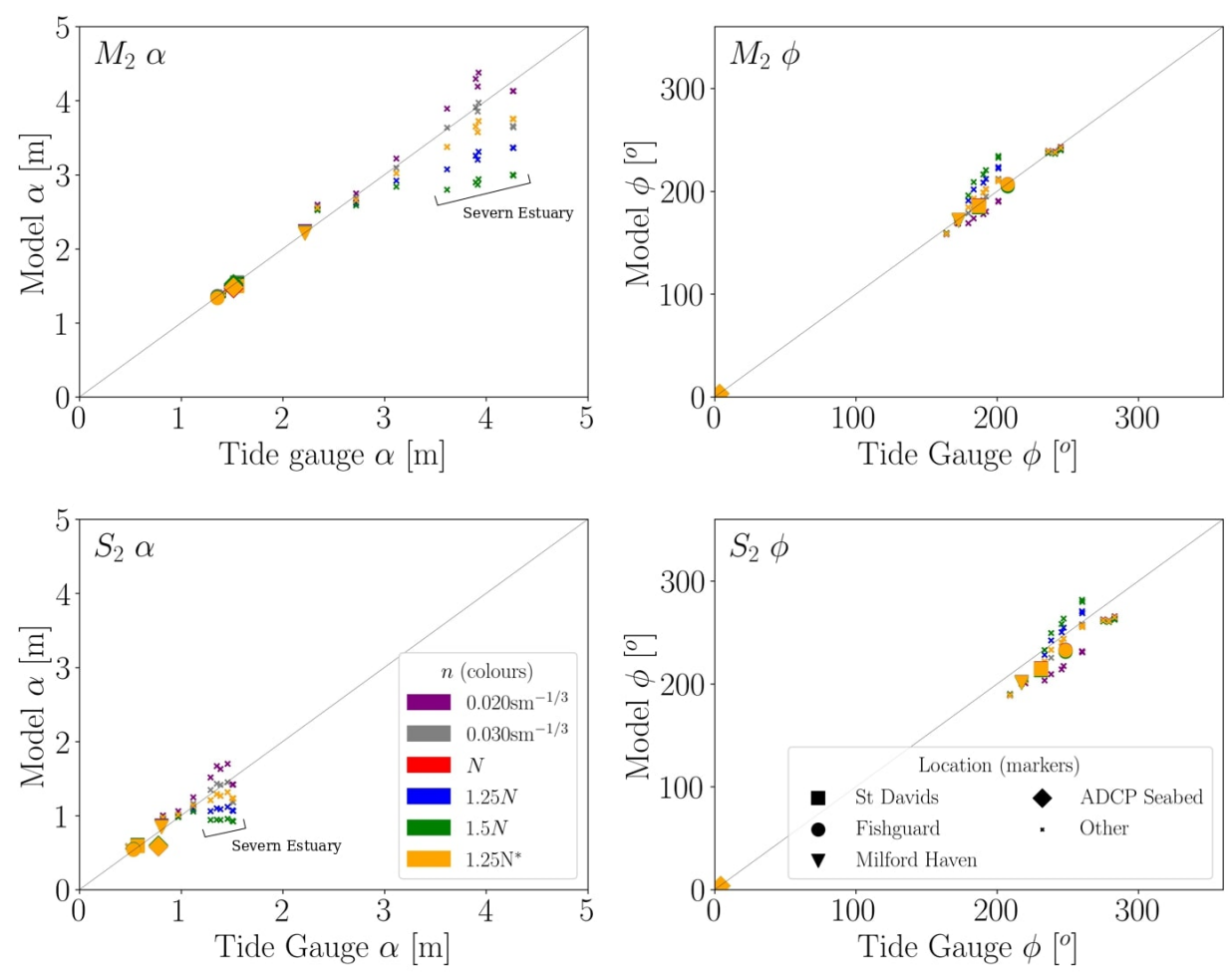

Figure 5: Comparing modelled and measured $M_{2}$ and $S_{2}$ tidal constituent amplitude $\alpha$ and phase $\phi$ at tide gauge locations for different Manning coefficient fields. Tide gauge locations are indicated in Fig. 19.

The two main aspects separating the different Manning coefficient configurations are spatial variability and scaling. Uniformly scaled configurations of the variable Manning coefficient field $(1.25 \mathrm{~N}$ and $1.5 \mathrm{~N})$ exhibit a notably reduced $R^{2}$ correlation against BODC equivalents of $M_{2}$ and $S_{2}$ amplitude $\alpha$, in comparison to other configurations. Meanwhile, the uniform constants $\left(0.02 \mathrm{sm}^{-1 / 3}\right.$ and $\left.0.03 \mathrm{sm}^{-1 / 3}\right)$ exhibit similar velocity 

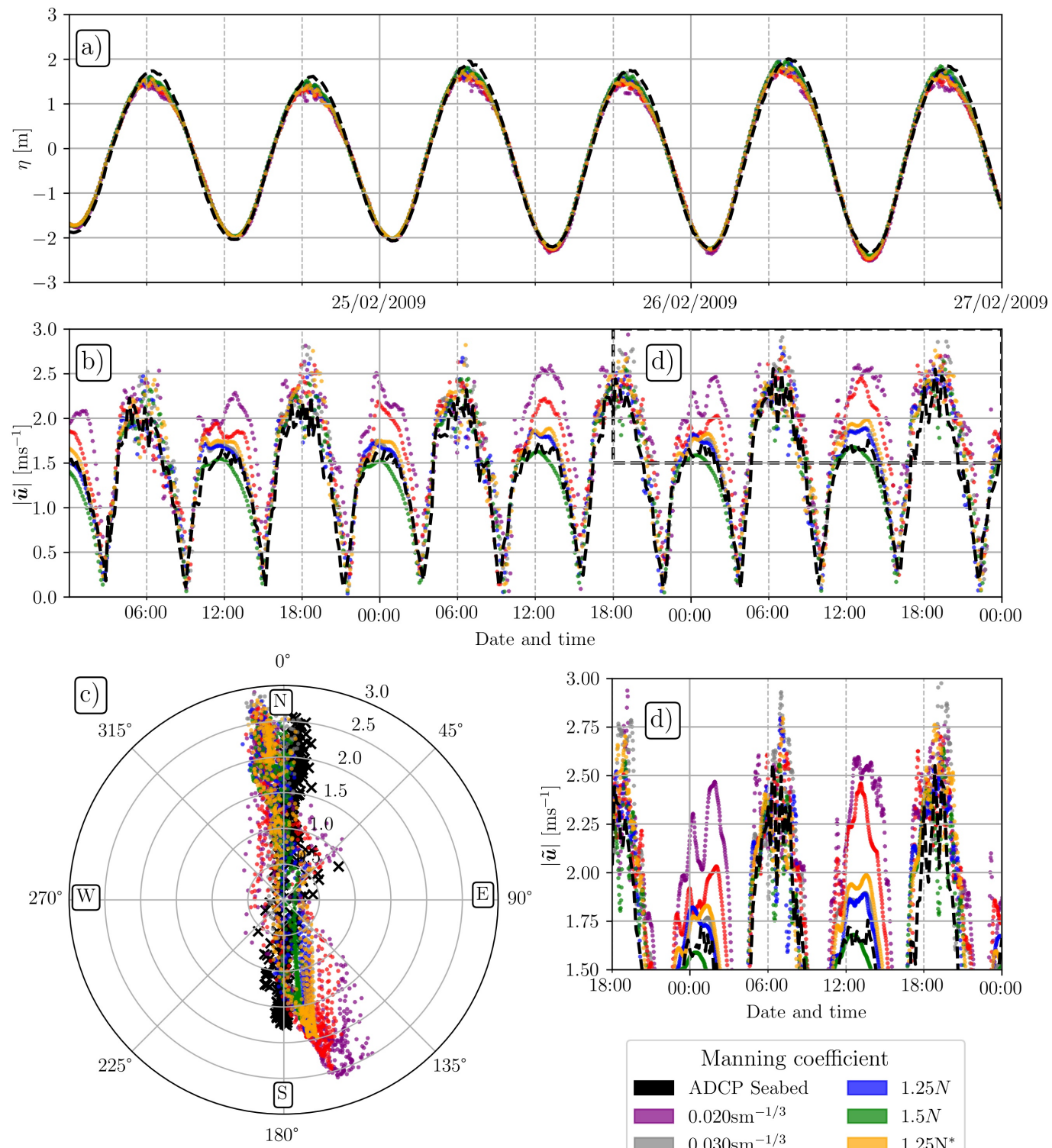

$\tilde{\boldsymbol{u}} \mid\left[\mathrm{ms}^{-1}\right]$

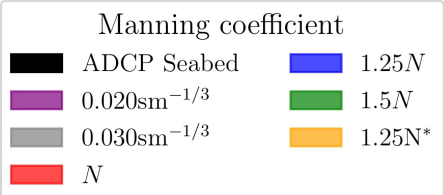

Figure 6: Seabed-mounted ADCP measurements of a) elevation $\eta$ and b), c), d) depth-averaged velocity magnitude $\tilde{\mathbf{u}}$ (see Fig. 4 for sample location) and equivalent Thetis model outputs. Survey conducted during a spring tide over four tidal cycles and displayed as a, b), d) time-series and c) a polar plot. Subplots a), b) and c) display a sub-sampling of every six values.

correlation to the configurations of spatially variable $N$ with the ADCP seabed survey. Little separates $0.03 \mathrm{sm}^{-1 / 3}$ with $1.25 \mathrm{~N}, 1.5 \mathrm{~N}$ and $1.25 \mathrm{~N}^{*}$ when comparing model outputs using vessel-mounted ADCP measurements. Model outputs in the ebb tide are generally better correlated with field measurements than the flood tide. Overall, the variably scaled Manning coefficient field $1.25 N^{*}$ is deemed to calibrate the model to the best degree. Further rationale behind selecting $1.25 N^{*}$ as the optimum is given in Figs. 5,6 and 7. which visualise comparisons of model outputs between Manning coefficient field configurations.

The source of the reduced correlation of $M_{2}$ and $S_{2}$ amplitude $\alpha$ in the $1.25 \mathrm{~N}$ and $1.5 \mathrm{~N}$ fields is indicated in Fig. 5 These points have been identified as tide gauges located in the Severn Estuary. Here, flow characteristics are largely driven by tidal resonance, and are thus highly sensitive to changes in seabed 
Flood tide 01/06/2012

Slack times: $12: 45$ \& 18:45
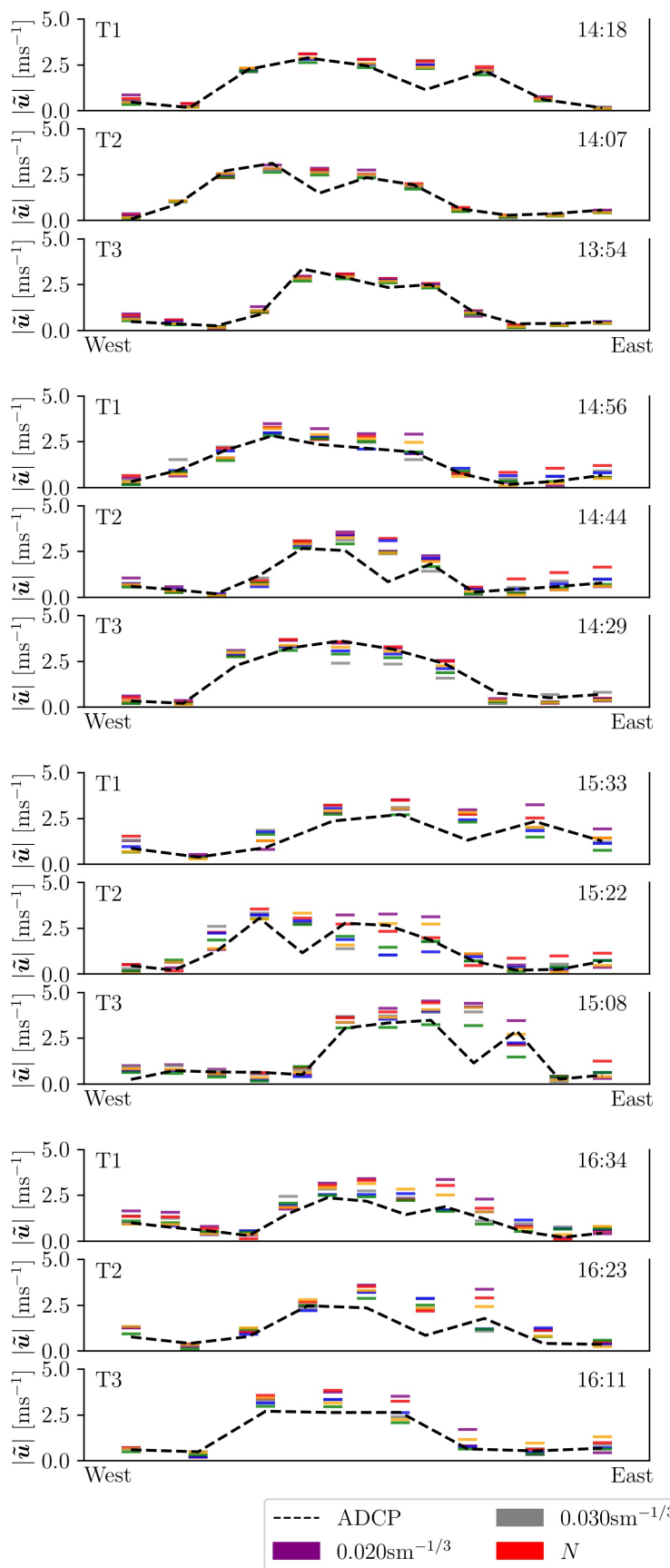

Ebb tide 02/06/2012

Slack times: 07:45 \& 13.45
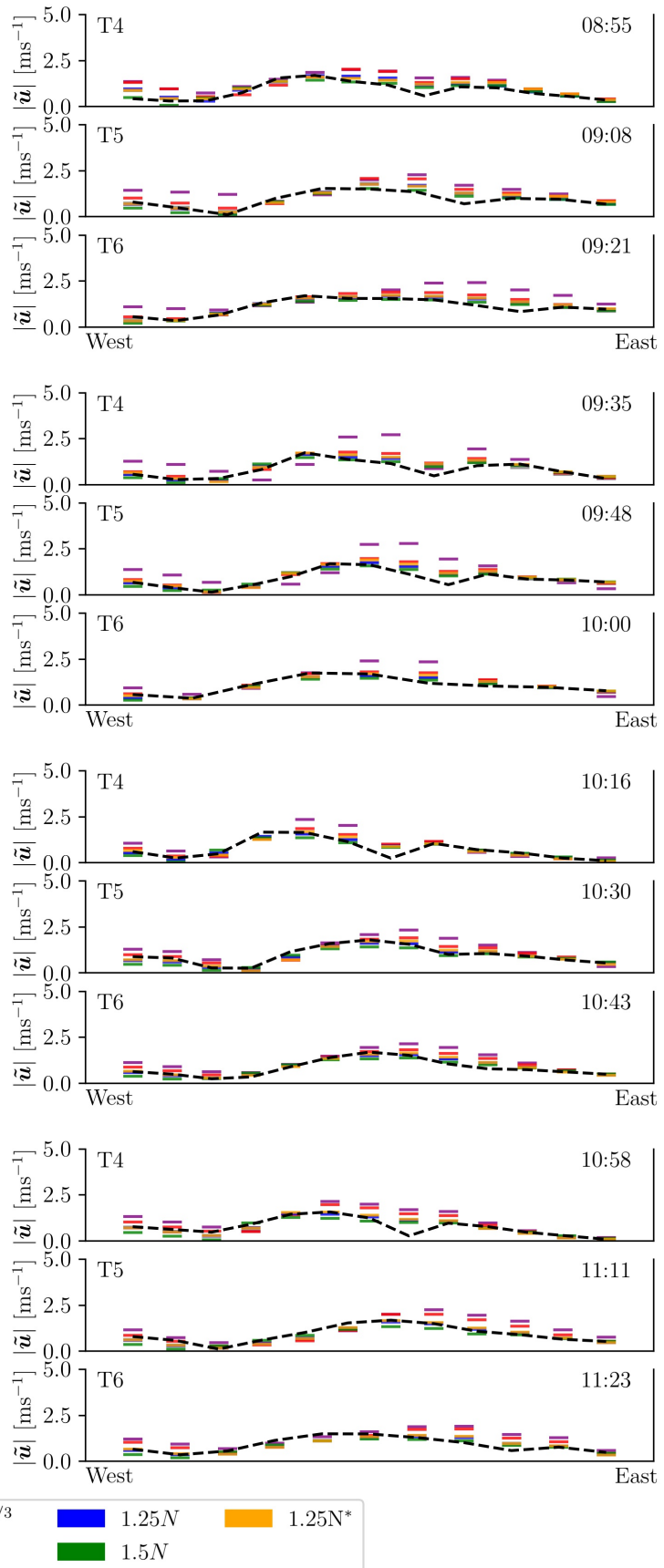

Figure 7: Depth- and time-averaged velocity magnitude of vessel-mounted ADCP field measurements $|\tilde{\mathbf{u}}|_{10}$ compared with equivalent model outputs $|\tilde{\mathbf{u}}|$ applying different Manning coefficient configurations. Results display most energetic periods of the survey across the six transects. Post-processing of the model outputs and field measurements is conducted as per the methodology in Section 3.2 The sampled easting bins are here evenly distributed from west to east.

characterisation. The manner in which $1.25 \mathrm{~N}$ and $1.5 \mathrm{~N}$ uniformly scale Manning coefficient across the domain significantly increases seabed friction in areas where it is already high. Tidal conditions in the Severn 
Estuary, where Manning coefficient is classed as "bedrock" (Table 1) over large areas, are therefore greatly affected by this scaling.

Notable discrepancies occur between configurations regarding depth-averaged velocity magnitude outputs $|\tilde{\mathbf{u}}|$ and the seabed-mounted ADCP survey. This is highlighted in Fig. 6 $\mathrm{d}$, where model velocity peaks can differ from the ADCP survey by over $1 \mathrm{~ms}^{-1}$. Where a lower Manning coefficient is applied $\left(n=0.02 \mathrm{sm}^{-1 / 3}\right.$, $N$ ) periods of high velocity generally exceed ADCP equivalents. This suggests insufficient flow resistance. Model configurations employing $n=0.03 \mathrm{sm}^{-1 / 3}, 1.25 \mathrm{~N}, 1.5 \mathrm{~N}$ and $1.25 N^{*}$ all exhibit a better fit with the field measurements in these periods of the tide. $1.5 \mathrm{~N}$ tends to lose some of the temporal volatility of $|\tilde{\mathbf{u}}|$ present in the ADCP survey. Conversely $n=0.03 \mathrm{sm}^{-1 / 3}$ contains numerous readings which far exceed it.

Fig. 7 illustrates comparisons between vessel-mounted ADCP field measurements and equivalent model outputs, sampled as per Section 3.2. The four most energetic circuits in the flood and ebb tide are displayed across all six transects. Results indicate the largest errors occurring during periods of high depth-averaged velocity magnitude $\left(|\tilde{\mathbf{u}}|_{10}\right.$ and $\left.|\tilde{\mathbf{u}}|\right)$ in the centre of the channel in the flood tide. These readings also exhibit the highest differences in $|\tilde{\mathbf{u}}|$ output between the various Manning coefficient configurations. $N, 1.5 N$ and $1.25 N^{*}$ provide the closest match with the field measurements in numerous occurrences of these high velocity times and regions.

In summary, the Manning coefficient field $1.25 N^{*}$ provides the best model calibration throughout the domain in terms combining $R^{2}$ correlation with visual comparisons. This is a reflection of the manner in which this field combines unaltered parameterisations of bed classification observations in the majority of the domain (as with $N$ ), with scaling in areas of interest as a localised tuning parameter.

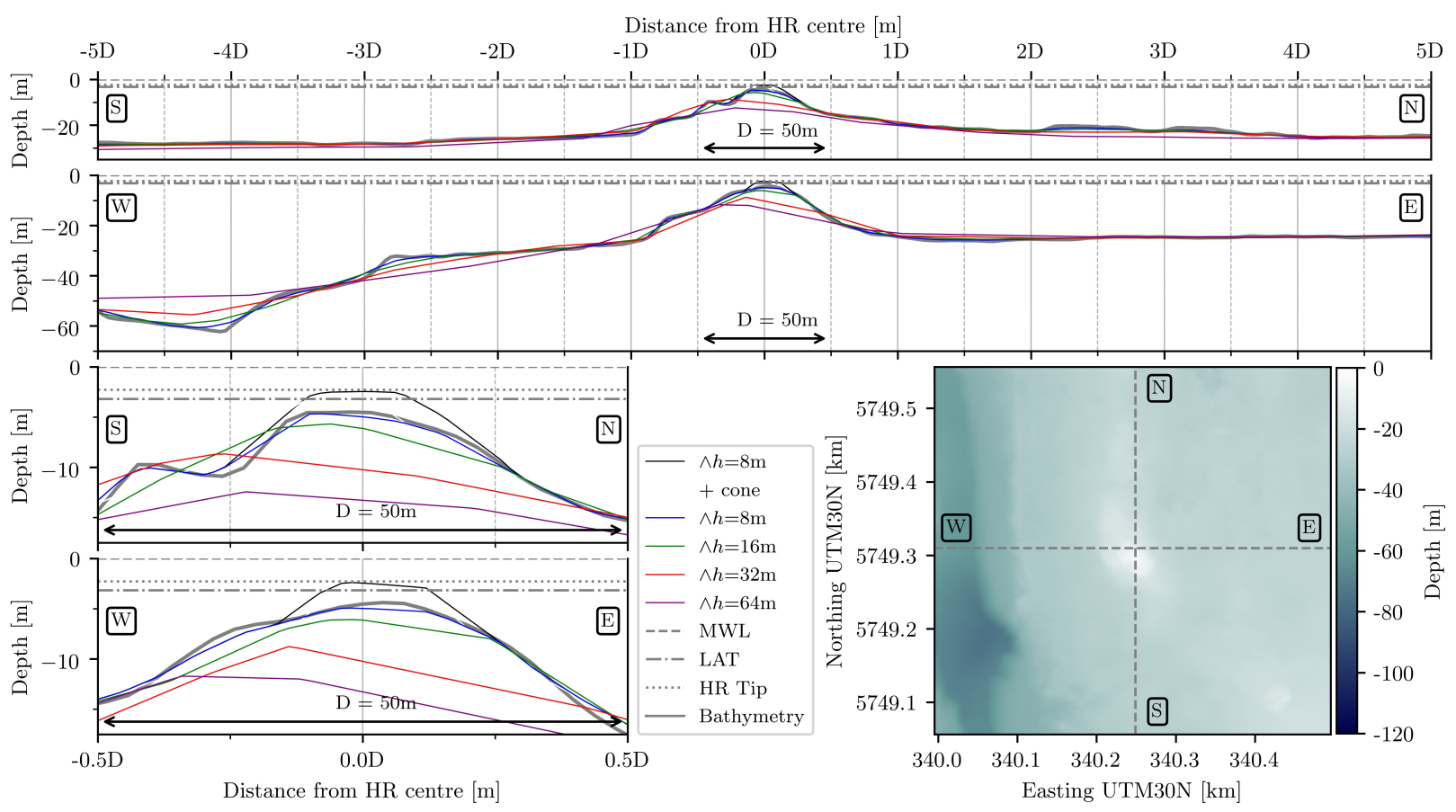

Figure 8: Horse Rock bathymetry field measurements from the Hydrographic Office (HO), including South-North (S-N) and West-East (W-E) cross-sections (top two frames respectively, with corresponding magnifications bottom-left). Interpolation of bathymetry onto meshes with different minimum mesh element lengths $(\wedge h)$ is indicated, including the implementation of a conical structure (the thin black line identified with $\wedge h=8 \mathrm{~m}+$ cone) to increase the height of Horse Rock to $+0.9 \mathrm{~m}$ Lowest Astronomical Tide (LAT). Depth is relative to MSL, corrected from LAT. 


\subsection{Investigating impact of mesh resolution}

A smaller mesh element size in the areas surrounding prominent features permits finer resolution of marine environment representation. The impact of increasing $\wedge h$ on both seabed geometry and hydrodynamic output is explored. Fig. 8 demonstrates how mesh resolutions in Fig. 1 $\mathrm{d}-\mathrm{g}$ in the numerical model setup interpolate bathymetry observations to represent the geometry of Horse Rock. The artificial conical feature is removed initially, and the minimum mesh element size $\wedge h$ is subsequently increased from $8 \mathrm{~m}$, to $16 \mathrm{~m}, 32 \mathrm{~m}$ and $64 \mathrm{~m}$ (Fig. 1). Fig. 9 explores how coarsening the mesh resolution could potentially misrepresent hydrodynamics in the strait. The snapshots indicate peak flood and ebb spring tide, the model applying calibrated Manning coefficient field $1.25 N^{*}$. Internal axes represent easterly $\tilde{u}$, northerly $\tilde{v}$ and magnitude of $|\tilde{\mathbf{u}}|$ depth-averaged velocities at increasing distances from Horse Rock in multiples of its half-height diameter $D=50 \mathrm{~m}$.



Figure 9: Comparison of spring tide velocity fields in the wake of Horse Rock with minimum mesh element sizes $\wedge h=8 \mathrm{~m}$ (with and without the addition of the cone to the bathymetry), $16 \mathrm{~m}, 32 \mathrm{~m}$ and $64 \mathrm{~m}$ around bathymetric features. Grid labelling indicates the distance from the tip of horse rock by the half height diameter of Horse Rock $D(\mathrm{~m})$. Internal axes indicates velocity. 
Alterations to Horse Rock geometry and resulting wake structure can be observed with each change in bathymetry discretisation. Removing the conical structure reduces the tip of Horse Rock to below LAT of the north-south trench is simultaneously reduced. In Fig. 9 the ebb wake disappears upon removal of the conical structure. Meanwhile, the flood wake is significantly reduced, before dissipating completely when increasing the minimum mesh element size to $\wedge h=16 \mathrm{~m}$. On the flood tide, applying $\wedge h=32 \mathrm{~m}$ leads to a redirection of the flow to the south of Horse Rock, in what appears to be the formation of a recirculation zone. This effect can be observed to a greater extent at $\wedge h=64 \mathrm{~m}$. Changes to flow structure on the ebb tide between configurations are subtler than on the flood tide. The velocity deficit is decreased and subsequently disappears when removing the conical feature and then increasing to $\wedge h=16 \mathrm{~m}$, respectively. Minimal additional differences can be observed when coarsening the mesh further.

\subsection{Analysis of Ramsey Sound hydrodynamics}

ADCP field surveys and outputs of the optimum calibrated model (1.25N* Manning coefficient field, minimum mesh element length $\wedge h=8 \mathrm{~m}$ ) deliver a comprehensive representation of flow conditions in Ramsey Sound. Here, we identify and illustrate notable hydrodynamic features which occur in the strait.
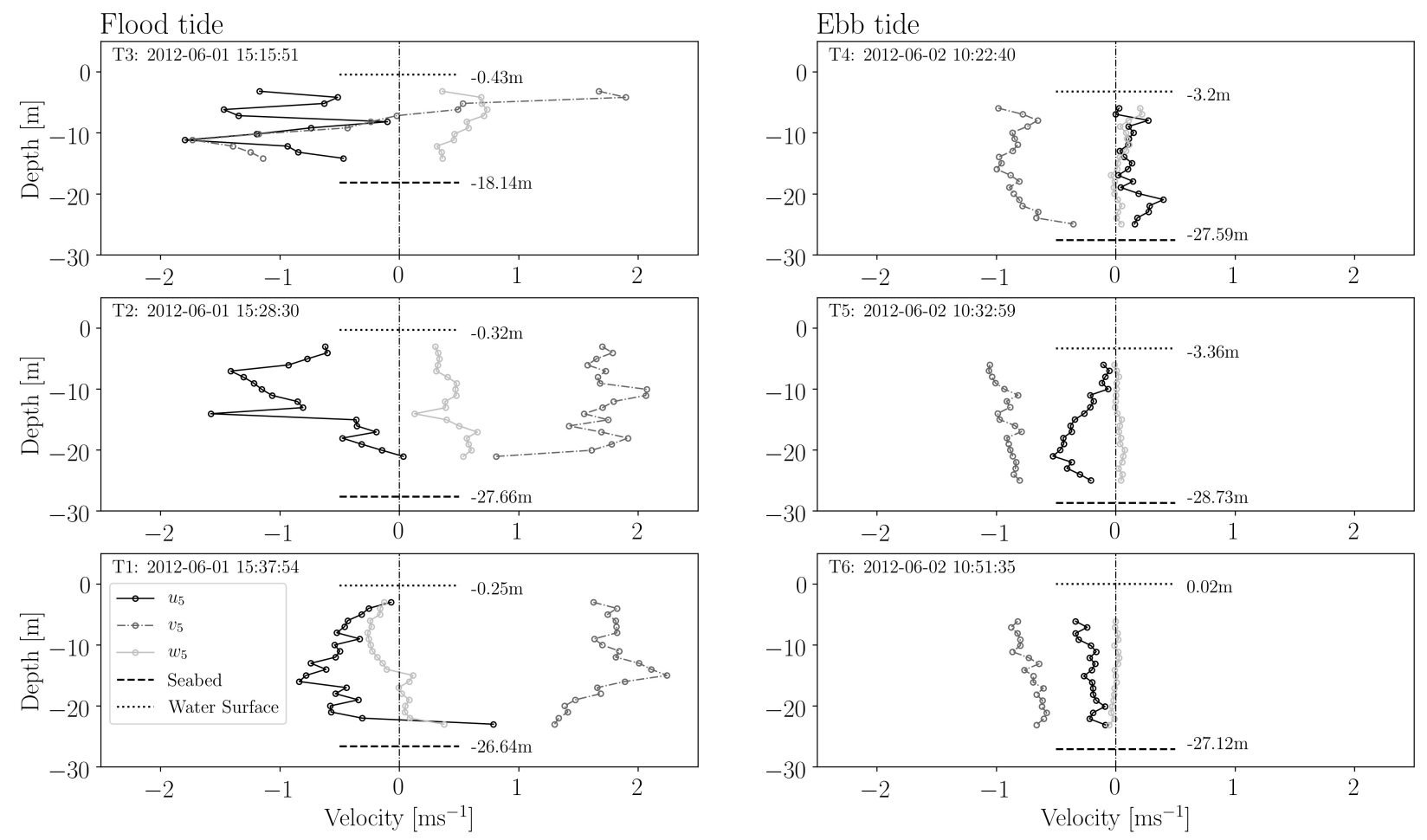

Figure 10: Vertical profiles of time-averaged velocity components $\left(u_{5}, v_{5}\right.$ and $\left.w_{5}\right)$ from the vessel-mounted ADCP surveys along the stream-wise centre line of Horse Rock during peak flood and ebb tides. Depth is relative to mean sea level (MSL).

\subsubsection{ADCP measurements}

ADCP surveys in Ramsey Sound provide a snapshot of 3D hydrodynamic features that may be otherwise obscured or misrepresented by depth-averaged numerical modelling assumptions. Some highlighted trends have been noted in previous literature $[8,53,54$. In analysing velocity measurements $(u, v$ and $w)$ from 
the vessel-mounted ADCP survey, a sliding $5 \mathrm{~s}$ time averaging window $\left(u_{5}, v_{5}\right.$ and $\left.w_{5}\right)$ is applied. A lower averaging window is applied than during model calibration so as to conserve water column structure. Meaurements along the stream-wise centre line of Horse Rock are extracted from peak ebb and flood flow for each transect, and presented in Fig. 10. Water elevation is derived from the seabed-mounted ADCP survey, which is harmonically reconstructed to the displayed timestamps of the vessel-mounted ADCP readings. Flood tide readings indicate relatively complex flow immediately downstream from Horse Rock (T3), with northward velocity $v_{5}$ reversals occurring through the water column. Vertical velocity $w_{5}$ decreases towards $0 \mathrm{~ms}^{-1}$, signalling a gradual return from upwelling to quasi-2D flow. Meanwhile, readings on the ebb tide indicate predominantly quasi-2D flow throughout.
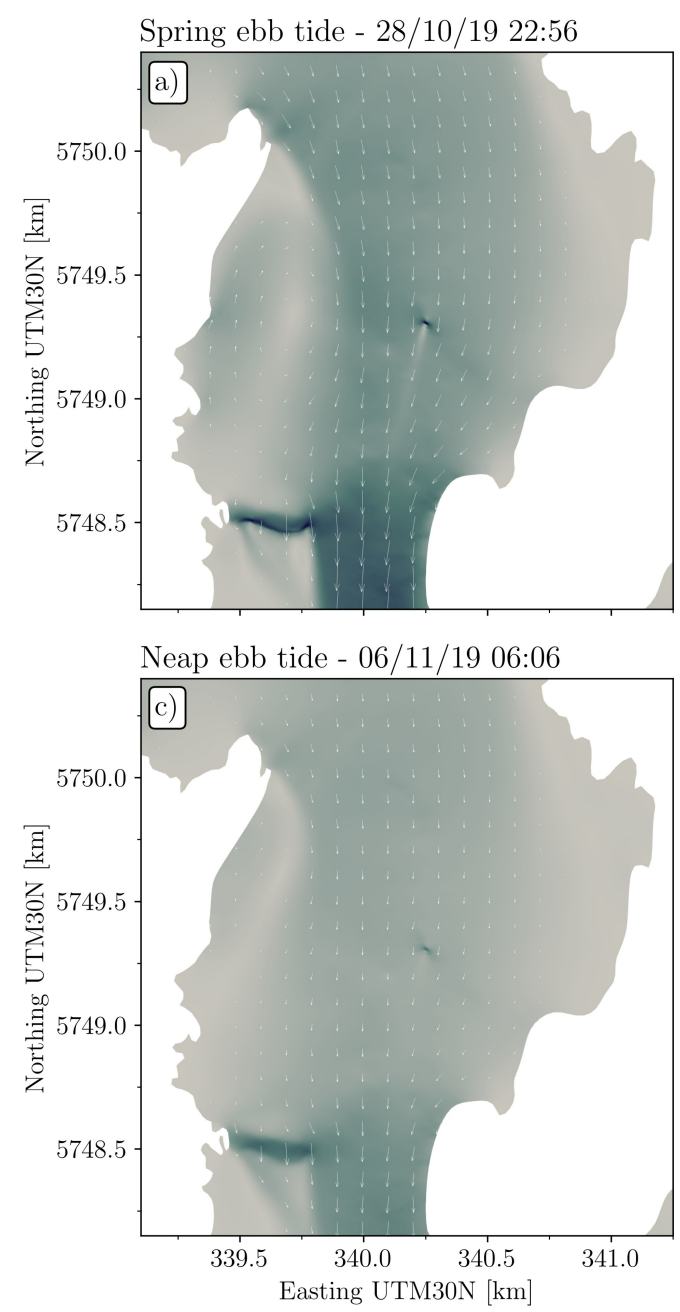

Spring flood tide - 29/10/19 06:10

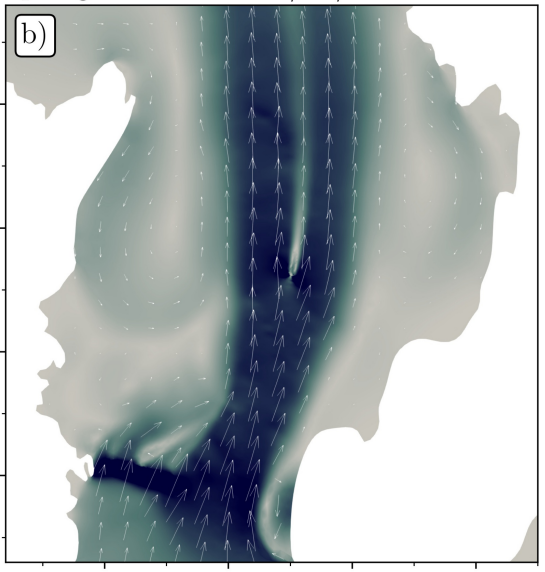

Neap flood tide - 06/11/19 00:50

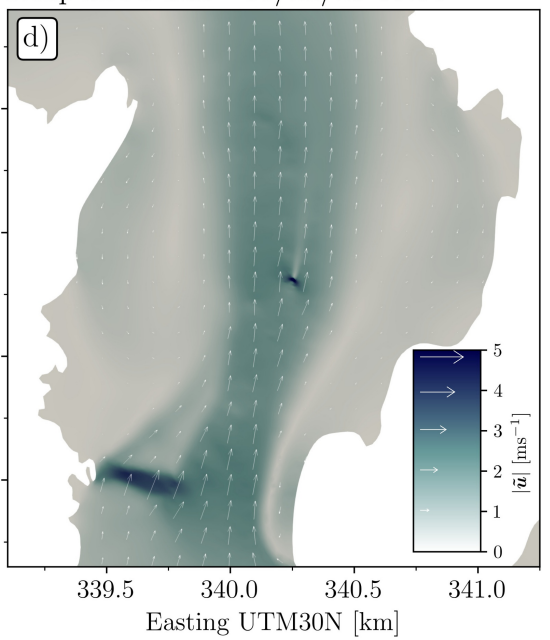

Figure 11: Modelled depth-averaged velocity magnitude $|\tilde{\mathbf{u}}|$ in Ramsey Sound during peak ebb and flood tide velocities under spring and neap conditions.

\subsubsection{Hydrodynamic model outputs}

A full spring-neap tidal cycle from 29 October 2019 to 28 November 2019 is considered, applying a timestep size of $\Delta t=100 \mathrm{~s}$. Fig. 11 displays depth-averaged velocity magnitude $|\tilde{\mathbf{u}}|$ in Ramsey Sound at peak currents during spring and neap tides. Flux across the strait at horizontal transects six Horse Rock half 
height diameters $(6 D)$ north of Horse Rock are indicated in Table 3 . The tidal asymmetry is apparent, with velocity upstream from Horse Rock being much higher on the spring flood than the spring ebb tide. This is in part driven by "The Bitches", its breadth and shallow depths effectively creating a narrowing of the strait which accelerates the flow in all scenarios covered.

Table 3: Volumetric flow rate (or flux) in $\mathrm{m}^{3} \mathrm{~s}^{-1}$ in hydrodynamic model at transects spanning the entire channel, six half height diameters of Horse Rock $(6 D)$ north and south of Horse Rock over spring-neap tidal conditions. Positive values indicate northerly flow.

\begin{tabular}{c|c|c}
\hline \hline Tide stage & Date \& time & Flux $6 D$ North $\left[\mathrm{m}^{3} \mathrm{~s}^{-1}\right]$ \\
\hline Spring ebb & $28 / 10 / 1922: 56$ & $-36,487$ \\
Spring flood & $29 / 10 / 1906: 10$ & 65,533 \\
Neap ebb & $06 / 11 / 1906: 06$ & $-25,050$ \\
Neap flood & $06 / 11 / 1900: 50$ & 30,428 \\
\hline \hline
\end{tabular}
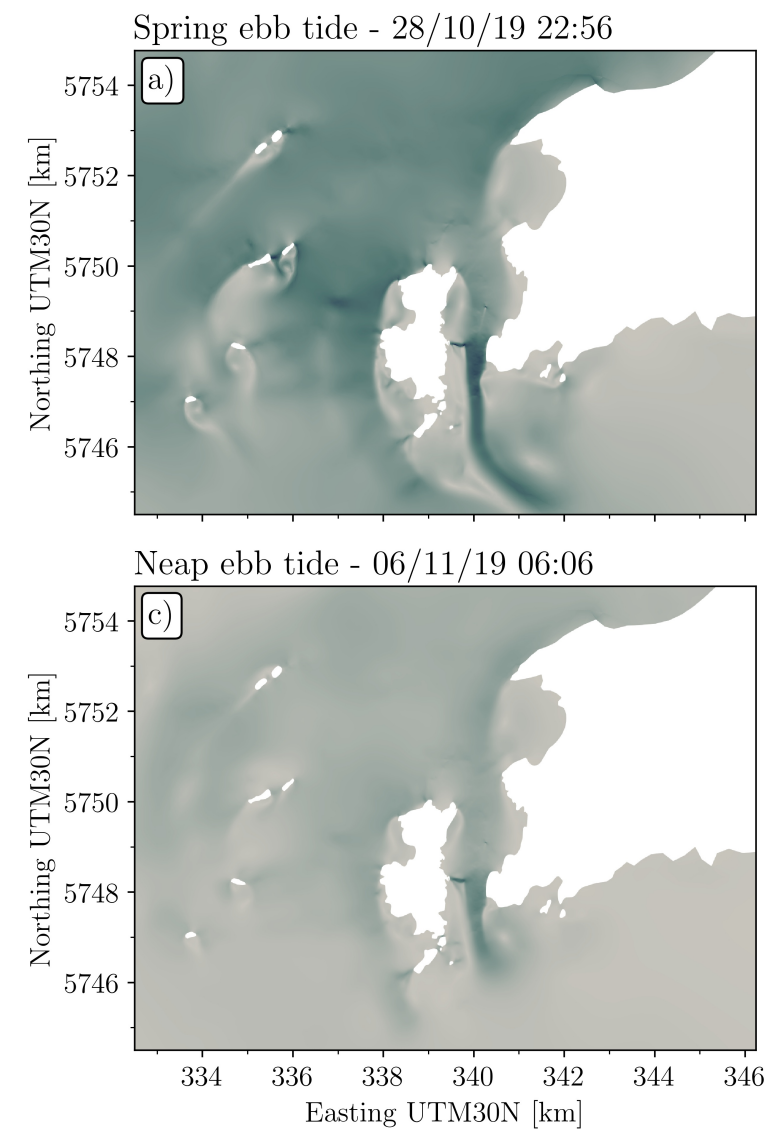

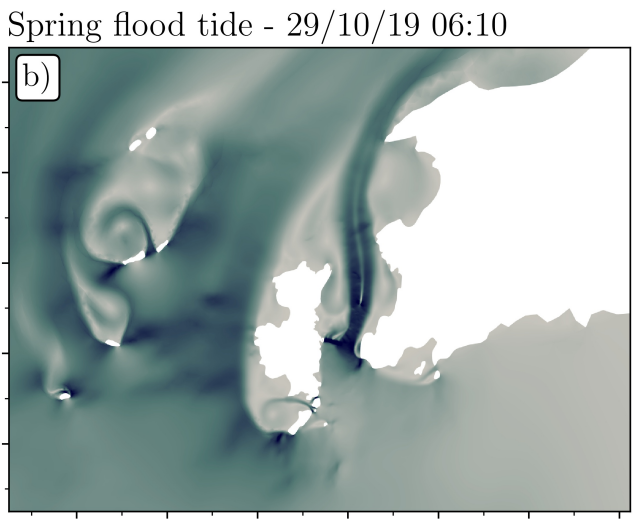

Neap flood tide - 06/11/19 00:50

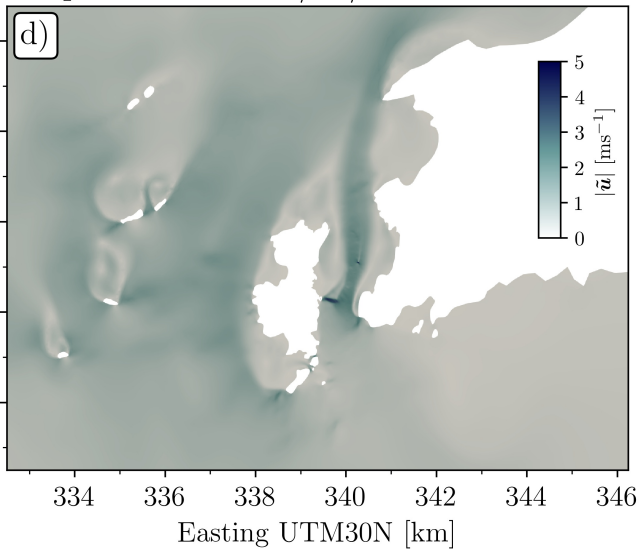

Figure 12: Modelled depth-averaged velocity magnitude $|\tilde{\mathbf{u}}|$ in the coastal regions surrounding Ramsey Sound during peak ebb and flood tide velocities under spring and neap conditions.

The amplification of depth-averaged velocity magnitude $|\tilde{\mathbf{u}}|$ on the flood spring tide results in a significant 300 wake structure in lee of Horse Rock. The $|\tilde{\mathbf{u}}|$ upstream from Horse Rock exceeds $5 \mathrm{~ms}^{-1}$, a velocity which is maintained on the outer parts of the resulting wake but falls to less than $1 \mathrm{~ms}^{-1}$ immediately north of the feature, in the inner section of the wake. The width of the wake encompasses roughly a third of the 
breadth of the strait, featuring recirculation zones on the outer edges. During the spring ebb tide, where Horse Rock pierces the water, a slight reduction in $|\tilde{\mathbf{u}}|$ from roughly 2 to $1 \mathrm{~ms}^{-1}$ occurs, but quickly recovers. Velocity vectors in Fig. 11 illustrate the high degree to which northerly (streamwise) depth-averaged velocity $\tilde{v}$ dominates the magnitude vector of $|\tilde{\mathbf{u}}|$.

Fig. 12 shows snapshots of depth-averaged velocity $|\tilde{\mathbf{u}}|$ at the same instance as Fig. 11, but at a larger scale. One can observe the full extent of the Horse Rock wake during flood tide, contained within a high velocity jet which reaches far beyond the north of Ramsey Island, and the conclusion of the wake, curving around the Pembrokeshire coast. A similar, but subtler, effect occurs also on the ebb tide. Notably, these regions of increased velocity appear to be triggered by the narrowing of the strait at "The Bitches".
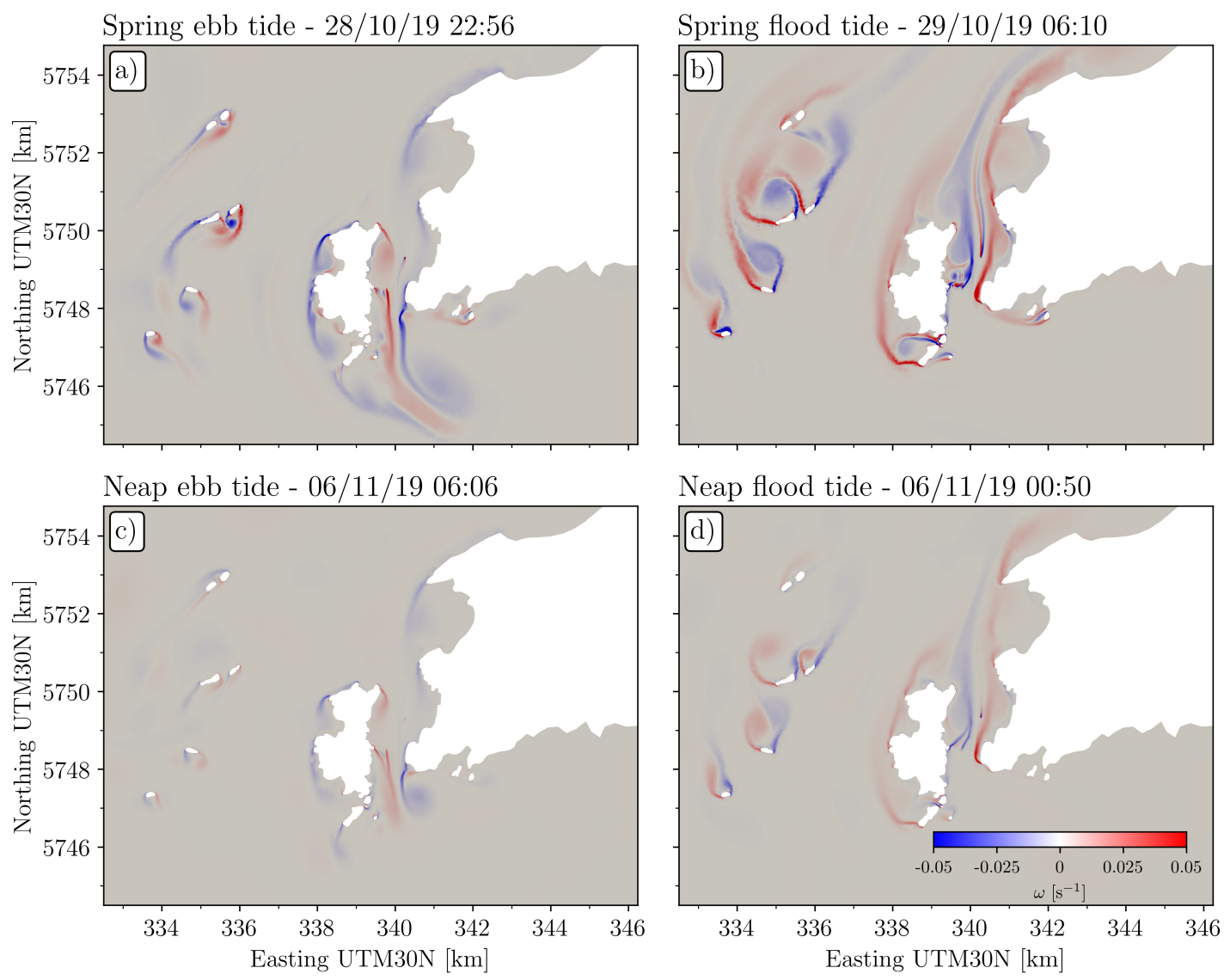

Figure 13: Modelled vorticity around Ramsey Sound and the surrounding waters under different tidal conditions.

The regional scale vorticity $\omega$ is diagnosed by solving a weak form of the vorticity equation (with the corresponding strong or PDE form being $\omega=-\frac{\partial \tilde{u}}{\partial y}+\frac{\partial \tilde{v}}{\partial x}$ ), as outlined by Vouriot et al. [55]. In Fig. 13 , regions of high vorticity appear to stem from "The Bitches", Bishop and Clerks and in some cases, Horse

315 Rock. It can be observed how coastal features lead to the formation of pronounced separation zones, that evolve with the the tide.

\section{Discussion}

It has been demonstrated how pronounced bathymetric features in Ramsey Sound constructively/destructively interfere with the flow path. The available power $P$ from a stream of water is approxi- 
mately proportional to the cube of the unperturbed fluid speed $\nu$ (as shown by $P \propto \nu^{3}$ ) [56, highlighting the advantage of tidal stream turbine TST deployment in higher velocity areas. The velocity deficit experienced downstream of Horse Rock on the high current flood tide could therefore have a significant bearing on the performance of TSTs, requiring strategic positioning to avoid both the wake as well as the lower velocity zones either side of the high velocity central flow. Furthermore, misaligning the axial flow on a TST has been shown to have negative consequences on performance and durability [57, a potential factor highlighted by the high vorticity in the lee of Horse Rock (Fig. 13p. Therefore, sufficient representation of the hydrodynamics is required to model and maximise the performance and reliability of potential projects. An accurate numerical model of the strait thus has value in investigating both wake characteristics in the lee of these submerged features, and as a platform from which to investigate the tidal energy resource.

A focal point of this study is the limitations in modelling choices when representing the marine environment. Both seabed geometry and roughness characteristics are investigated. For the former, replication of bathymetry measurements and other observations is recommended, given that seabed geometry is an easily quantifiable input metric. A greater degree of uncertainty is present in characterising the roughness of the seabed. While spatial variability is afforded by bed classification observations, scaling of the variable field is used as a tuning parameter to calibrate against hydrodynamic field measurements of the domain. Here, we discuss how focusing on each of these model aspects affects it's accuracy, which in turn affects functionality for its intended application, or any area of research which requires a high degree of accuracy in characterising coastal flow structures.

\subsection{Calibrating Manning coefficient configuration}

Tidal elevation $\eta$ (Fig. 6a) and constituent amplitude $\alpha$ and phase $\phi$ (Fig. 5) model outputs are barely altered between different uniform constant and spatially variable $\left(N\right.$ and $\left.N^{*}\right)$ Manning coefficient $n\left(\mathrm{sm}^{-1 / 3}\right)$ configurations. The exception is high $n$ locations such as Severn Estuary, which according to observations has large areas exhibiting over $n=0.05 \mathrm{sm}^{-1 / 3}$, classified as "bedrock". Meanwhile, greater model output disparity is present between different Manning coefficient configurations in high velocity periods and zones displayed in Fig. 6and7. Generation from TSTs will predominantly occur during periods of high flow velocity, so accurate characterisation of the hydrodynamics here is important for tidal resource assessment models. As such, higher sensitivity to changes in $n$ is observed in local velocities, with improved model agreement occurring in the scaled configurations of the variable field $N$. This justifies the use of variable scaling $N^{*}$ as a tool for localised tuning of the physical representation in the area of interest, where the required optimisation of velocities might not reflect the scaling required to maximise the agreement in elevations elsewhere.

By integrating seabed composition observations into the numerical model, specifically the representation of bed shear stress throughout the domain, this study has demonstrated the potential importance of considering this as a variable rather than a uniform field. However, it is notable that little variation exists in the BGS observations in characterising the seabed in Ramsey Sound itself. Furthermore, coastal and intertidal sections of the domain apply an estimation of bed class due to a lack of observations in these areas. Admiralty Charts suggest a more diverse seabed composition than is afforded by the BGS observations, describing zones with indistinct borders consisting of "rock", "sand, gravel, mud" and "sand, shells" 31 in areas all denoted by "medium gravel" in the BGS survey. A more detailed survey than carried out by BGS, specific to Ramsey Sound, could prove beneficial. If required, a more nuanced approach than the scaling method implemented

herein could apply discrete changes between bed class as a guide to tuning seabed friction. Alternatively, an adjoint approach has been shown to accurately infer Manning coefficient spatially from harmonic tidal constituents 58 . 


\subsection{Characterising seabed geometry}

In applying a computational mesh with minimum element size $\wedge h=8 \mathrm{~m}$ around key bathymetric features

365 studies. Fig. 9 demonstrates the necessity of applying such a refined mesh in capturing the complex flow structures in Ramsey Sound. Even coarsening resolution to $\wedge h=16 \mathrm{~m}$, what would still be considered quite a fine mesh, much of the wake structure on the flood tide is no longer captured. Coarsening to $\wedge h=32 \mathrm{~m}$ also leads to a redirection of the upstream flow. This is likely a result of the manner in which the geometry of Sound.

The smaller overall hydrodynamic changes in the ebb tide when increasing $\wedge h$ suggests that use of a highly refined mesh resolution surrounding prominent bathymetric features is less vital at lower velocities. However, the impact of implementing the artificial conical structure is evident on the ebb tide, its application capture submergence, or lack thereof, of bathymetric features at all stages of the tidal cycle, as piercing the water could induce significant change in the flow structure. Insufficient characterisation of the flow regime, both through an under-refined mesh or incomplete bathymetry survey over non-coastal intertidal areas, could have significant implications in the way turbines are deployed or operated. The poor reproduction of easterly could improve the characterisation of "The Bitches" and thus overall model validation. It is also worth noting that model interpretation of regional velocities should take into account coarser mesh resolution further from the immediate areas of interest. The vorticity metric, for example, is very sensitive to mesh refinement and could partly explain why vorticity is highest in Ramsey Sound (Fig. 13), where the mesh element size is the smallest.

Construction of multiple TSTs would need to consider the interactions of the resulting turbine wakes with existing submerged features. Considering the sensitivity of the flow path to these bathymetric features, further complications could arise should TSTs redirect the flow in a manner which erodes or changes bathymetric structures. A coarsening of the mesh serves to trim the tip of Horse Rock, affecting the computed rocky reef "The Bitches" could dramatically affect the favourable flow acceleration it contributes to. Adaptation to potential changes, such as the ability of a TST to yaw, could thus prove advantageous 59. This discussion highlights several important points: the performance of an array of TSTs is highly dependent on underlying flow structure, but in turn this flow structure is itself highly dependent on geometrical structure,

\section{Conclusions}

This study investigates common configuration choices in depth-averaged coastal models in representing the marine environment. Ramsey Sound, a tidal strait exhibiting high velocity currents considered for the testing and/or deployment of tidal stream turbines (TSTs), is regarded as a suitable case study. Ramsey Sound contains a variety of prominent bathymetric features which significantly influence localised and regional flow structures. The interest in Ramsey Sound for both potential TST deployment and field-based investigation of submerged bathymetric features calls for accurate characterisation of the complex and transient flow field. Furthermore, the strait permits testing of the limitations of depth-averaged models in characterising complex flow conditions.

We calibrate configurations of the model by comparing elevation and depth averaged velocity outputs with equivalent ADCP and tide gauge field measurements. Bed classification observations permit a spatially 
variable field of Manning coefficient for seabed roughness. This coefficient is adopted as a tuning parameter, comparing constants, a more typical approach, with scaled configurations of the variable field. A configuration locally scaling the variable field by 1.25 in the immediate area of interest is found to provide optimum correlation with the measured data, satisfying both far-field tidal elevations and local flow structures. The highest discrepancy between model configurations occurs in the high velocity areas in the centre of the strait. We recommend a more nuanced approach than numerical scaling, perhaps combining discrete alterations in bed class with a seabed sediment survey more focused in key areas than available here.

High resolution bathymetry observations provide a detailed characterisation of seabed geometry in Ramsey

Sound. Local prominent bathymetric features are found to require a finer computational mesh resolution $(\wedge h$ $=8 \mathrm{~m}$ ) than commonly applied in coastal models to avoid smoothing their high gradient. Furthermore, an additional artificial conical structure is applied on top of Horse Rock to match other accounts reporting drying at spring tide low water. The sensitivity of the flow structure to the geometry of Horse Rock via coarsening of the computational mesh highlights the importance of accurately representing small but influential features.

\section{Acknowledgements}

LM would like to acknowledge the financial support of an EPSRC PhD studentship award, grant number EP/R513052/1(18-22). AA acknowledges the support of NERC through the Industrial Innovation fellowship grant NE/R013209/2. MP acknowledges support from EPSRC under grants EP/M011054/1, EP/L000407/1, $\mathrm{EP} /$ R029423/1. The authors also thank Dr Chris Wooldridge for skippering the R/V Guiding Light during data collection, and Tidal Energy Limited (TEL) for providing the seabed measurements and their valuable input. Intertek Energy and Water Consultancy Services support this innovative research, and further information can be found at: http://www.intertek.com/energy-water/tidal-energy/

\section{CRediT authorship contribution statement}

Lucas Mackie: Conceptualization, Methodology, Software, Validation, Formal Analysis, Investigation, Writing - original draft, Visualization. Paul S. Evans: Resources, Writing - review \& editing. Magnus J. Harrold: Resources, Writing - review \& editing. Tim O'Doherty: Writing - review \& editing. Matthew D. Piggott: Conceptualization, Writing - review \& editing, Supervision, Funding Aquisition. Athanasios Angeloudis: Conceptualization, Methodology, Investigation, Writing - review \& editing, Supervision, Funding Aquisition.

\section{References}

[1] T. Kärnä, S. C. Kramer, L. Mitchell, D. A. Ham, M. D. Piggott, A. M. Baptista, Thetis coastal ocean model: Discontinuous Galerkin discretization for the three-dimensional hydrostatic equations, Geoscientific Model Development 11 (2018) 4359-4382.

[2] F. Harcourt, A. Angeloudis, M. D. Piggott, Utilising the flexible generation potential of tidal range power plants to optimise economic value, Applied Energy 237 (2019) 873-884.

[3] T. Adcock, S. Draper, G. Houlsby, A. Borthwick, On the tidal resource of the Pentland Firth, in: 4th International Conference on Ocean Energy, Dublin, Ireland, 2012, pp. 1-5.

[4] J. Thiébot, P. B. du Bois], S. Guillou, Numerical modeling of the effect of tidal stream turbines on the hydrodynamics and the sediment transport - application to the alderney race (raz blanchard), france, Renewable Energy 75 (2015) 356 - 365. 
[5] A. L. Baker, R. M. Craighead, E. J. Jarvis, H. C. Stenton, A. Angeloudis, L. Mackie, A. Avdis, M. D. Piggott, J. Hill, Modelling the impact of tidal range energy on species communities, Ocean \& Coastal Management 193 (2020) 105221.

[6] Miller, Jack and Hornigold, Thomas, Marine Renewables: UK Parliament POSTnote, 2020. URL: https://post.parliament.uk/research-briefings/post-pn-0625/.

[7] D. Haverson, J. Bacon, H. C. Smith, V. Venugopal, Q. Xiao, Modelling the hydrodynamic and morphological impacts of a tidal stream development in Ramsey Sound, Renewable Energy 126 (2018) 876 887.

[8] P. Evans, A. Mason-Jones, C. Wilson, C. Wooldridge, T. O’Doherty, D. O'Doherty, Constraints on extractable power from energetic tidal straits, Renewable Energy 81 (2015) 707-722.

[9] A. S. Bahaj, L. E. Myers, Shaping array design of marine current energy converters through scaled experimental analysis, Energy (2013).

[10] E. Zangiabadi, I. Masters, A. Williams, C. T.N., Characterisation of the Coastal Hydrology of Oceans Using 3D Computational Fluid Dynamics, in: 4th International Conference on Ocean Energy, Dublin, Ireland, 2012, pp. 1-6.

[11] I. Milne, A. Day, R. Sharma, R. Flay, The characterisation of the hydrodynamic loads on tidal turbines due to turbulence, Renewable and Sustainable Energy Review 56 (2016) 851-864.

[12] R. Martinuzzi, C. Tropea, The flow around surface-mounted, prismatic obstacles placed in a fully developed channel flow: (Data bank contribution), Journal of Fluids Engineering, Transactions of the ASME (1993).

[13] P. Ouro, C. A. M. E. Wilson, P. Evans, A. Angeloudis, Large-eddy simulation of shallow turbulent wakes behind a conical island, Physics of Fluids 29 (2017) 126601.

[14] S. W. Funke, S. C. Kramer, M. D. Piggott, Design optimisation and resource assessment for tidalstream renewable energy farms using a new continuous turbine approach, Renewable Energy 99 (2016) $1046-1061$.

[15] S. Funke, P. Farrell, M. Piggott, Tidal turbine array optimisation using the adjoint approach, Renewable Energy 63 (2014) $658-673$.

[16] G. Z. L., C. D. S., P. M. D., Identifying economically viable tidal sites within the alderney race through optimization of levelized cost of energy, Philosophical Transactions A 378 (2020) 1 - 20.

475 [17] N. Guillou, G. Chapalain, Numerical simulation of tide-induced transport of heterogeneous sediments in the english channel, Continental Shelf Research 30 (2010) 806-819.

[18] A. Pérez-Ortiz, A. G. Borthwick, J. McNaughton, A. Avdis, Characterization of the tidal resource in rathlin sound, Renewable Energy 114 (2017) 229 - 243. Wave and Tidal Resource Characterization.

[19] S. Serhadlioğlu, T. A. Adcock, G. T. Houlsby, S. Draper, A. G. Borthwick, Tidal stream energy resource assessment of the Anglesey Skerries, International Journal of Marine Energy (2013).

[20] S. Draper, T. Adcock, A. Borthwick, G. Houlsby, Estimate of the tidal stream power resource of the Pentland Firth, Renewable Energy 63 (2014) 650-657. 
[21] M.-S. R., J. Hill, S. C. Kramer, A. Avdis, P. A. Allison, M. D. Piggott, Tidal resource extraction in the Pentland Firth, UK: Potential impacts on flow regime and sediment transport in the Inner Sound of Stroma, Renewable Energy 76 (2015) 596-607.

[22] S. L. Ward, S. P. Neill, K. J. Van Landeghem, J. D. Scourse, Classifying seabed sediment type using simulated tidal-induced bed shear stress, Marine Geology 367 (2015) 94 - 104.

[23] K. J. Van Landeghem, K. Uehara, A. J. Wheeler, N. C. Mitchell, J. D. Scourse, Post-glacial sediment dynamics in the irish sea and sediment wave morphology: Data-model comparisons, Continental Shelf Research 29 (2009) 1723 - 1736.

[24] B. Guo, R. Ahmadian, P. Evans, R. A. Falconer, Studying the Wake of an Island in a Macro-Tidal Estuary, Water 12 (2020).

[25] D. Coles, L. Blunden, A. Bahaj, Assessment of the energy extraction potential at tidal sites around the Channel Islands, Energy 124 (2017) 171-186.

[26] W. Pan, S. C. Kramer, M. D. Piggott, Multi-layer non-hydrostatic free surface modelling using the discontinuous galerkin method, Ocean Modelling 134 (2019) 68 - 83.

[27] F. Rathgeber, D. A. Ham, L. Mitchell, M. Lange, F. Luporini, A. T. T. McRae, G.-T. Bercea, G. R. Markall, P. H. J. Kelly, Firedrake: automating the finite element method by composing abstractions, ACM Transactions on Mathematical Software 43 (2016) 24:1 - 24:27.

[28] I. Warren, H. Bach, Mike 21: a modelling system for estuaries, coastal waters and seas, Environmental Software 7 (1992) 229 - 240. 3rd International Software Exhibition for Environmental Science and Engineering.

[29] S. Goossens, K. Tan, D. Roose, A krylov-schwarz iterative solver for the shallow water equations, Physics and Chemistry of the Earth 23 (1998) 485 - 490.

[30] The Crown Estate, UK Wave and Tidal Key Resource Areas Project: Summary Report), 2012. URL: http://www.marineenergywales.co.uk/wp-content/uploads/2016/01/Summary-Report-FINAL . pdf.

[31] GPS Nautical Charts, A Ramsey Sound with The Bishops and Clerks (Ma1. rine Chart : 1482 1), 2014. URL: http://www.gpsnauticalcharts.com/main/1482_ 1-a-ramsey-sound-with-the-bishops-and-clerks-nautical-chart.html.

[32] British Oceanographic Data Centre, UK Tide Gauge Network Data, Technical Report, British Oceanoa graphic Data Centre, 2017. URL: https://www.bodc.ac.uk/data/hosted_data_systems/sea_level/ uk_tide_gauge_network/processed/.

[33] M. Lewis, S. P. Neill, P. E. Robins, M. R. Hashemi, Resource assessment for future generations of tidal-stream energy arrays, Energy (2015).

[34] S. L. Ward, P. E. Robins, M. J. Lewis, G. Iglesias, M. R. Hashemi, S. P. Neill, Tidal stream resource characterisation in progressive versus standing wave systems, Applied Energy 220 (2018) 274-285.

[35] P. E. Robins, S. P. Neill, M. J. Lewis, S. L. Ward, Characterising the spatial and temporal variability of the tidal-stream energy resource over the northwest European shelf seas, Applied Energy (2015). 
[51] R. L. Soulsby, Tidal current boundary layers, in: B. Le Mehaute, D. M. Hanes (Eds.), The Sea, Volume 9: Ocean Engineering Science, volume 9, Harvard University Press, 2005, pp. 0-10.

[52] Tidal Energy Limited, DeltaStream Demonstration Ramsey Sound, Pembrokeshire: Scoping Report, 555 2008. URL: https://tethys.pnnl.gov/sites/default/files/publications/TEL_Scoping_Report_ 2008.pdf. installation sites, Proceedings of the 4th International Conference on Ocean Energy (2012).

[37] R. D. Pingree, D. K. Griffiths, Sand transport paths around the british isles resulting from $\mathrm{m} 2$ and $\mathrm{m} 4$ tidal interactions, Journal of the Marine Biological Association of the United Kingdom (1979).

[38] M. Togneri, I. Masters, Micrositing variability and mean flow scaling for marine turbulence in ramsey sound, Journal of Ocean Engineering and Marine Energy 2 (2016) 35-46.

[39] T. Kärnä, B. de Brye, O. Gourgue, J. Lambrechts, R. Comblen, V. Legat, E. Deleersnijder, A fully implicit wetting-drying method for DG-FEM shallow water models, with an application to the Scheldt Estuary, Computer Methods in Applied Mechanics and Engineering 200 (2011) 509-524.

[40] A. Angeloudis, S. C. Kramer, A. Avdis, M. D. Piggott, Optimising tidal range power plant operation, Applied Energy 212 (2018) 680-690.

[41] A. Angeloudis, S. C. Kramer, N. Hawkins, M. D. Piggott, On the potential of linked-basin tidal power plants: An operational and coastal modelling assessment, Renewable Energy 155 (2020) 876-888.

[42] S. Balay, S. Abhyankar, M. F. Adams, J. Brown, P. Brune, K. Buschelman, L. Dalcin, V. Eijkhout, W. D. Gropp, D. Kaushik, M. G. Knepley, L. C. McInnes, K. Rupp, B. F. Smith, S. Zampini, H. Zhang, H. Zhang, PETSc Users Manual, Technical Report ANL-95/11 - Revision 3.7, Argonne National Laboratory, 2016. URL: http://www.mcs.anl.gov/petsc

[43] A. Avdis, A. S. Candy, J. Hill, S. C. Kramer, M. D. Piggott, Efficient unstructured mesh generation for marine renewable energy applications, Renewable Energy 116 (2018) 842-856.

[44] C. Geuzaine, J.-F. Remacle, Gmsh Reference Manual, Technical Report 4.6.0, GNU General Public License, 2020. URL: https://gmsh.info/.

[45] Seazone Solutions Ltd., Edina Digimap Service, Hydrospatial one, gridded bathymetry, 2014. URL: http://digimap.edina.ac.uk/marine/.

[46] Bangor University, UKHO Tide Gauge Network Data, 2017.

[47] G. D. Egbert, S. Y. Erofeeva, Efficient Inverse Modeling of Barotropic Ocean Tides, Atmos. Oceanic Technol. (2002) 183-204.

[48] M. Solano, M. Canals, S. Leonardi, Barotropic boundary conditions and tide forcing in split-explicit high resolution coastal ocean models, Journal of Ocean Engineering and Science 5 (2020) 249 - 260.

[49] YouTube, Horse Rock, Ramsey Sound, Pembrokeshire, 2014. URL: https://www. youtube.com/watch? v=o1PQSwHkxjk, Upload User: utubemematt, Accessed: 11/06/2020.

[50] British Geological Survey, BGS Geology: marine sediments 250k — DigSBS250, 2011. URL: https: //www.bgs.ac.uk/products/offshore/DigSBS250.html

[36] M. Togneri, I. Masters, Comparison of marine turbulence characteristics for some potential turbine 
[53] P. Evans, E. Lazarus, A. Mason-Jones, D. O'Doherty, T. O'Doherty, Wake Characteristics of a Natural Submerged Pinnacle and Implications for Tidal Stream Turbine Installations, in: 11th European Wave and Tidal Energy Conference, 2015, pp. 110. URL: https://www.researchgate.net/publication/281589471_Wake_characteristics_of_a_ natural_submerged_pinnacle_and_implications_on_tidal_stream_turbine_installations.

[54] P. Evans, S. Armstrong, C. Wilson, I. Fairley, C. Wooldridge, I. Masters, Characterisation of a Highly Energetic Tidal Energy Site with Specific Reference to Hydrodynamics and Bathymetry, in: 10th European Wave and Tidal Energy Conference, 2013, pp. 1-11. URL: https://www.researchgate.net/publication/257869016_Characterisation_of_a_Highly_ Energetic_Tidal_Energy_Site_with_Specific_Reference_to_Hydrodynamics_and_Bathymetry.

[55] C. V. M. Vouriot, A. Angeloudis, S. C. Kramer, M. D. Piggott, Fate of large-scale vortices in idealized tidal lagoons, Environmental Fluid Mechanics 19 (2019) 329-348.

[56] A. S. Bahaj, Generating electricity from the oceans, Renewable and Sustainable Energy Reviews 15 (2011) 3399-3416.

[57] C. Frost H., P. S. Evans, M. J. Harrold, A. Mason-Jones, T. O’Doherty, D. O'Doherty, The impact of axial flow misalignment on a tidal turbine, Renewable Energy 113 (2017) 1333-1344.

[58] S. Warder, A. Angeloudis, S. C. Kramer, C. Cotter, M. Piggott, A comparison of bayesian inference and gradient-based approaches for friction parameter estimation, EarthArXiv (2020).

575 [59] C. Frost, C. Morris, A. Mason-Jones, D. O'Doherty, T. O'Doherty, The effect of tidal flow directionality on tidal turbine performance characteristics, Renewable Energy 78 (2015) 609-620. 